Prepared in cooperation with National Park Service, Montezuma Castle National Monument

Removal of Nonnative Slider Turtles (Trachemys scripta) and Effects on Native Sonora Mud Turtles (Kinosternon sonoriense) at Montezuma Well, Yavapai County, Arizona

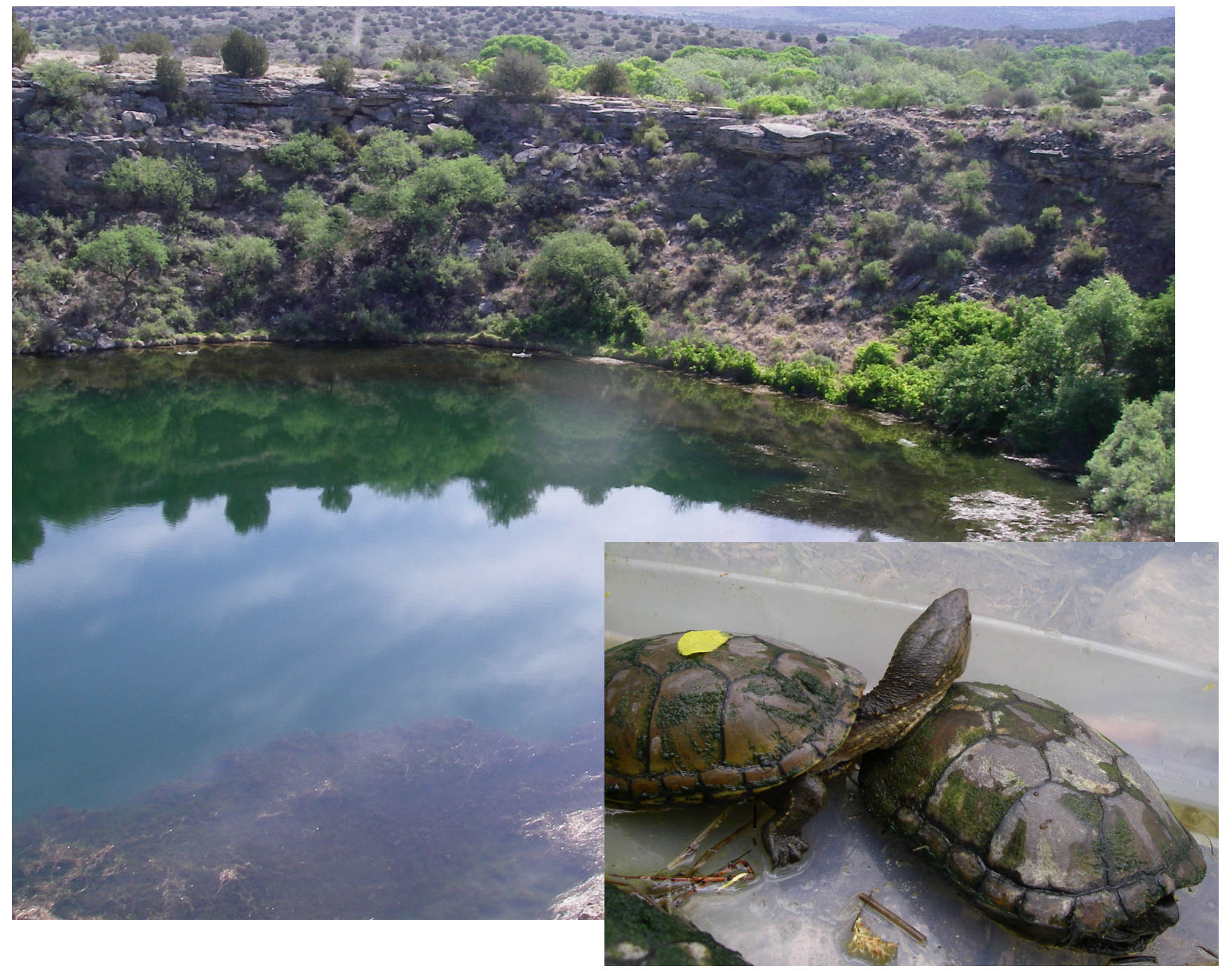

Open-File Report 2010-1177 
Cover: View of Montezuma Well, Montezuma Castle National Monument, Arizona, and (inset) two large Sonora mud turtles captured at Montezuma Well. (U.S. Geological Survey photos.) 
Prepared in cooperation with National Park Service, Montezuma Castle National Monument

Removal of Nonnative Slider Turtles (Trachemys scripta) and Effects on Native Sonora Mud Turtles (Kinosternon sonoriense) at Montezuma Well, Yavapai County, Arizona

By Charles A. Drost, Jeffrey E. Lovich, Sheila V. Madrak, and A.J. Monatesti

Report Series Open-File Report 2010-1177

U.S. Department of the Interior

U.S. Geological Survey 


\section{U.S. Department of the Interior \\ KEN SALAZAR, Secretary}

\section{U.S. Geological Survey \\ Marcia K. McNutt, Director}

U.S. Geological Survey, Reston, Virginia: 2011

For product and ordering information:

World Wide Web: http://www.usgs.gov/pubprod

Telephone: 1-888-ASK-USGS

For more information on the USGS-the Federal source for science about the Earth, its natural and living resources, natural hazards, and the environment:

World Wide Web: http://www.usgs.gov

Telephone: 1-888-ASK-USGS

Suggested citation:

Drost, C.A., Lovich, J.E., Madrak, S.V., and Monatesti, A.J., 2011, Removal of nonnative slider turtles (Trachemys scripta) and effects on native Sonora mud turtles (Kinosternon sonoriense) at Montezuma Well, Yavapai County, Arizona: U.S. Geological Survey Open-File Report 2010-1177, 48 p. [http://pubs.usgs.gov/of/2010/1177/].

Any use of trade, product, or firm names is for descriptive purposes only and does not imply endorsement by the U.S. Government.

Although this report is in the public domain, permission must be secured from the individual copyright owners to reproduce any copyrighted material contained within this report. 


\section{Contents}

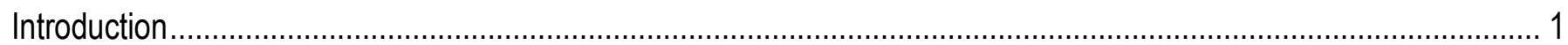

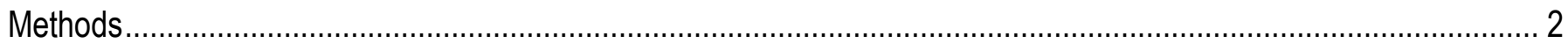

Study Area

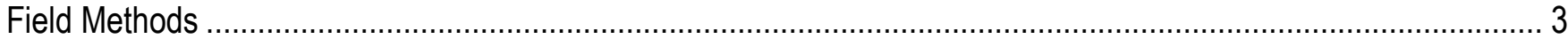

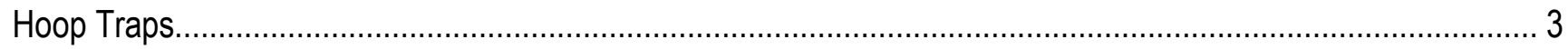

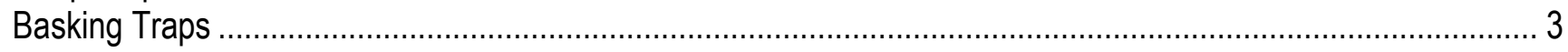

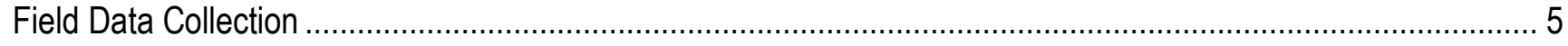

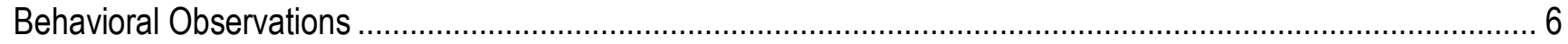

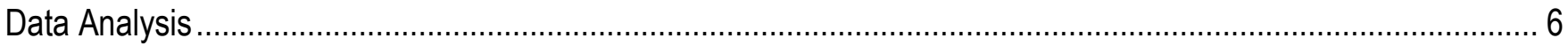

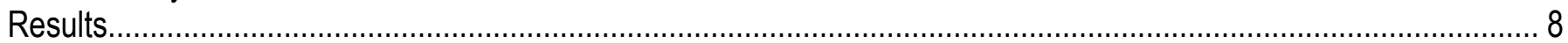

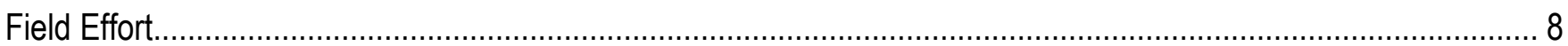

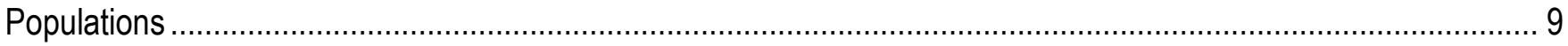

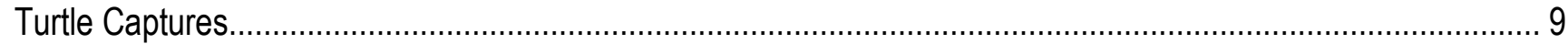

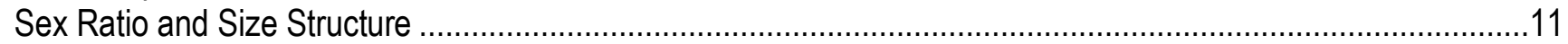

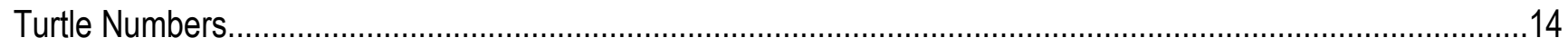

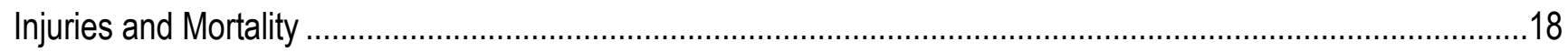

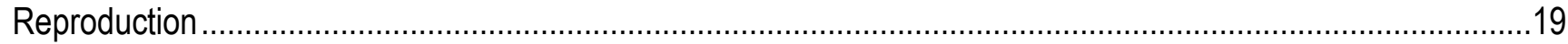

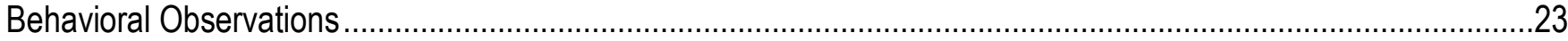

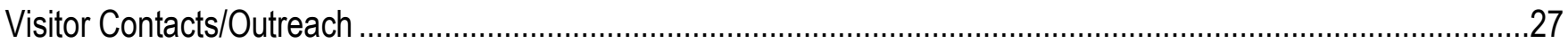

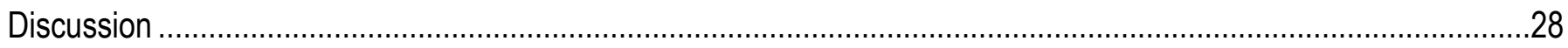

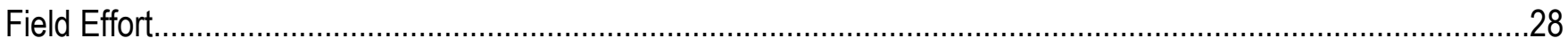

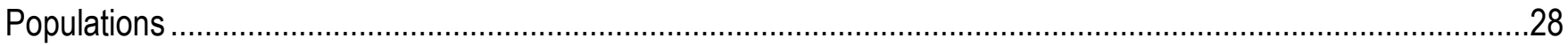

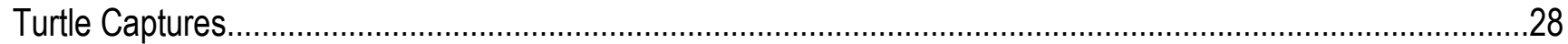

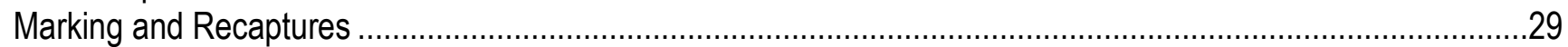

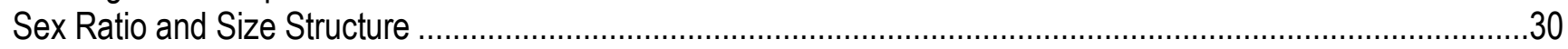

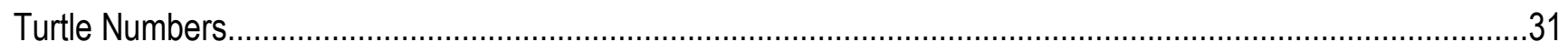

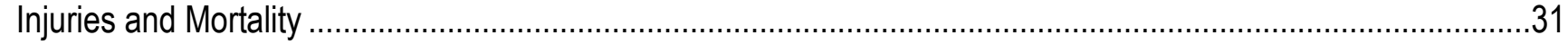

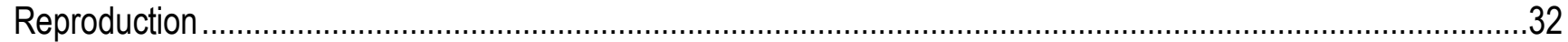

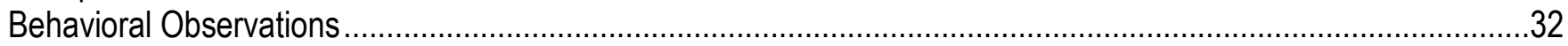

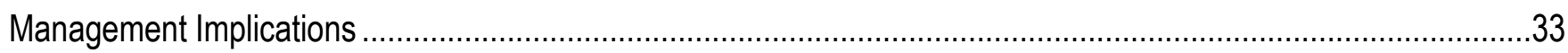

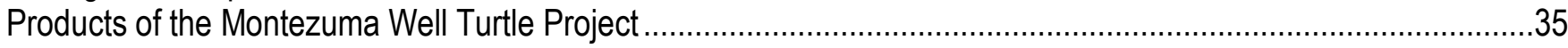

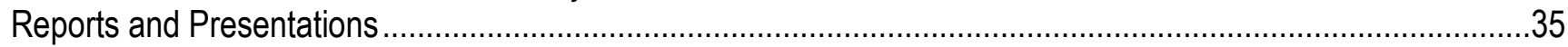

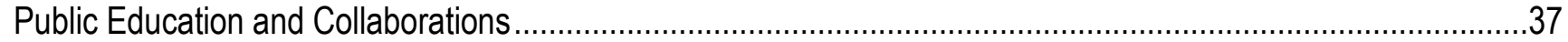

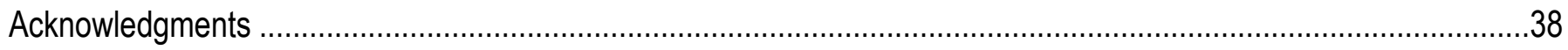

References Cited ..............................................................................................................................

Appendix 1. Description of morphological measurements and associated codes used in a study of Sonora

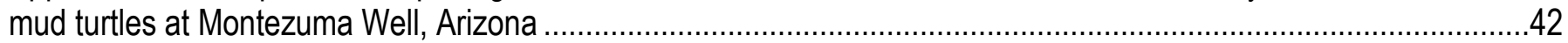

Appendix 2. Population monitoring scheme for turtles at Montezuma Well ...............................................................46 


\section{Figures}

1. Two hoop traps in place at the edge of aquatic vegetation on the west side of Montezuma Well .4

2. Marking system used to uniquely identify turtles captured at Montezuma Well, Arizona: Sonora

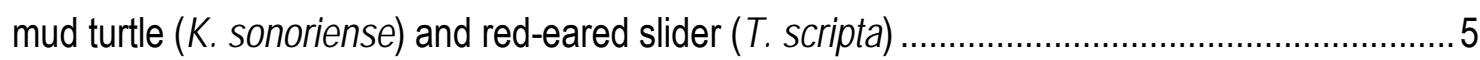

3. Aerial photo of Montezuma Well, Arizona, showing GIS grid map overlay used to note locations of individual turtles during behavioral observations conducted in 2007 and 2008 ...................... 7

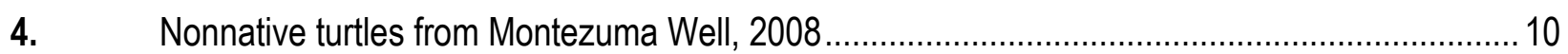

5. Hatchling mud turtle found along Beaver Creek near Montezuma Well, Arizona, in July $2007 \ldots 12$

6. Capture rates of mud turtles at Montezuma Well, Arizona, in June-August 1983 ...................... 15

7. Capture rates of mud turtles at Montezuma Well, Arizona, in July-November $1999 \ldots \ldots \ldots \ldots \ldots \ldots . . . . . .16$

8. Capture rates of mud turtles at Montezuma Well, Arizona, in May-October $2007 \ldots \ldots \ldots \ldots \ldots \ldots . . . . . . . . . .16$

9. Capture rates of mud turtles at Montezuma Well, Arizona, in March-September 2008 ............. 17

10. Comparison of capture rates of Sonora mud turtles at Montezuma Well during three trapping studies: Rosen (1987; fieldwork in 1983), Malone (1999), and this study (2007 and 2008) ....... 17

11. Radiograph showing female Sonora mud turtle with eight eggs............................................ 21

12. Daily activity pattern of Sonora mud turtles and red-eared sliders at Montezuma Well, Arizona, April through October 2007, based on systematic observations from the rim of the Well........... 24 


\section{Tables}

1. Distribution of turtle trapping effort at Montezuma Well, Arizona, in 2007 and 2008.

2. Total records of Sonora mud turtles (Kinosternon sonoriense) and red-eared sliders (Trachemys scripta) in 2007 and 2008 in Montezuma Well and adjacent Beaver Creek, Arizona.

3. Total captures of Sonora mud turtles (Kinosternon sonoriense) and red-eared sliders (Trachemys scripta) in 2007 and 2008 by trap type, in Montezuma Well and adjacent Beaver

Creek, Arizona ......

4. Sex ratios of Sonora mud turtles from Beaver Creek, Montezuma Well, and overall (Beaver

Creek and the Well combined) from captures in 2007 and 2008.

5. Carapace length $(\mathrm{mm})$ of Sonora mud turtles trapped in 2007 and 2008 at Beaver Creek and

Montezuma Well

6. Captures of nonnative turtles at Montezuma Well, Arizona, including species, sex, carapace length, and weight

7. Population estimates for Sonora mud turtles in Montezuma Well, Arizona, in 2007 and 2008... 18

8. Comparison of population estimates for Sonora mud turtles at Montezuma Well from studies by

Rosen (1983), Malone (1999), and this study $(2007,2008)$ 18

9. Injuries in Sonora mud turtles, in relation to size class. 19

10. Numbers and percent of female Sonora mud turtles found to be gravid at Montezuma Well and adjacent Beaver Creek, Arizona, in 2007 and 2008r 21

11. Detailed reproductive history of female Sonora mud turtles captured multiple times in 2007 and 2008 at Montezuma Well and adjacent Beaver Creek, Arizona 22

12. Summary of basking observations for Sonora mud turtles and red-eared sliders at Montezuma Well, Arizona, in 2007 and 2008 23 
13. Comparison of female reproductive rate in first and second halves of season, between Rosen's (1987) data in 1983 and observations in 2007 and 2008, at Montezuma Well, Arizona 32 


\title{
Removal of Nonnative Slider Turtles (Trachemys scripta) and Effects on Native Sonora Mud Turtles (Kinosternon sonoriense) at Montezuma Well, Yavapai County, Arizona
}

\author{
By Charles A. Drost, ${ }^{1}$ Jeffrey E. Lovich, ${ }^{1}$ Sheila V. Madrak, ${ }^{1,} 2$ and A.J. Monatesti ${ }^{1,3}$
}

\section{Introduction}

The National Park Service (NPS) estimates that 234 national parks contain nonnative, invasive animal species that are of management concern (National Park Service, 2004).

Understanding and controlling invasive species is thus an important priority within the NPS (National Park Service, 1996). The slider turtle (Trachemys scripta) is one such invasive species. Native to the Southeastern United States (Ernst and Lovich, 2009), as well as Mexico, Central America, and portions of South America (Ernst and Barbour, 1989), the slider turtle has become established throughout the continental United States and in other locations around the world (Burke and others, 2000).

Slider turtle introductions have been suspected to be a threat to native turtles (Holland 1994; da Silva and Blasco, 1995), however, there has not been serious study of their effects until recently. Cadi and Joly (2003) found that slider turtles outcompeted European pond turtles (Emys orbicularis) for preferred basking sites under controlled experimental conditions, demonstrating for the first time direct competition for resources between a native and an exotic turtle species. Similarly, Spinks and others (2003) suggested that competition for basking sites between slider turtles and Pacific pond turtles (Actinemys marmorata) was partly responsible for the decline of Pacific pond turtles observed at their study site in California. They concluded that the impact of introduced slider turtles was "almost certainly negative" for the western pond turtle. In the most recent critical study to assess the effects of introduced slider turtles on native turtles, Cadi and Joly (2004) demonstrated that European pond turtles that were kept under experimentally controlled conditions with slider turtles lost body weight and exhibited higher rates of mortality than in control groups of turtles comprised of the same species, demonstrating potential population-level effects on native species.

Slider turtles are not native to Arizona but have been introduced in several areas in the southern and central part of the State, including Montezuma Well (the Well). The only native turtle at the Well is the Sonora mud turtle (Kinosternon sonoriense). Interactions between sliders and mud turtles have not been investigated at the Well or elsewhere. However, basking sites

\footnotetext{
${ }^{1}$ U.S. Geological Survey, Southwest Biological Science Center, 2255 N. Gemini Drive, Flagstaff, AZ 86001.

2 Joint Doctoral Program in Ecology; San Diego State University/University of California, Davis; Department of Biology; 5500 Campanile Drive; San Diego; CA 92182.

${ }^{3}$ National Park Service, Lake Mead National Recreation Area, Environmental Compliance, 601 Nevada Way, Boulder City, NV 89005.
} 
preferred by aquatic turtles are rare at the Well, suggesting one potential avenue for resource competition between sliders and Sonora mud turtles. In this study, we collected data on both species to evaluate the possible effects of slider turtles on Sonora mud turtles at Montezuma Well. During live trapping in the spring, summer, and early fall of 2007 and 2008, we removed slider turtles that we captured in the Well. We also collected ecological data on the mud turtles captured in the trapping effort. Separate behavioral observations of the turtles in the Well provided additional information on the ecology of the two species in the unusual environment of the Well, and also of interactions between the sliders and mud turtles. In this report, we describe the results of $2 \mathrm{yr}$ of study of the turtles of Montezuma Well. We incorporate older data on the mud turtles in the Well to assess long-term population trends and potential response to the introduced slider turtles. We also report on aspects of basic ecology for the poorly understood Sonora mud turtle. The National Park Service requested that we incorporate public outreach as part of this research effort, so we also describe the outreach efforts associated with the turtle study.

\section{Methods}

\section{Study Area}

Montezuma Well is a large collapsed travertine spring mound located in northeastern Yavapai County, Arizona, near the town of McGuireville. The spring has an output of approximately 4,200 L/min (1,100 gal/min) and forms a large pond within the walls of the Well that is roughly circular in outline and measures approximately $112 \mathrm{~m}$ in diameter and up to $17 \mathrm{~m}$ deep (Blinn, 2008; Cole and Barry, 1973). The aquifer supplying the spring flows through calcareous rock of the Verde Formation, and the water that issues into the Well is highly carbonated from passage through and dissolution of this limestone. Owing in large part to the high carbonate levels, the waters of the Well form a unique aquatic ecosystem that is low in overall diversity but rich in endemic species (Blinn and Sanderson, 1989; O'Brien and Blinn, 1999). This system is characterized by (1) a nearly constant water temperature of $21^{\circ} \mathrm{C}$; (2) a remarkably high dissolved $\mathrm{CO}_{2}$ concentration as high as $500 \mathrm{mg} / \mathrm{l}$; (3) a simplified aquatic food web; (4) several narrowly endemic species of plants and invertebrates; (5) the absence of fish, amphibians, and several major groups of aquatic insects, probably because of the very high $\mathrm{CO}_{2}$ concentration of the water; and (6) one species of native turtle, the Sonora mud turtle, along with the nonnative slider turtle.

The Well and associated prehistoric Native American dwelling sites and cultural remains are protected as a unit of Montezuma Castle National Monument. The Montezuma Well unit is in the Verde River drainage at an elevation of 1,060-1,110 m (3,480-3,650 ft) and includes a portion of Wet Beaver Creek. Vegetation in the area contains a mix of semidesert grassland and Sonoran and Chihuahuan desert scrub, with a well-developed cottonwood riparian association along Beaver Creek (Rowlands, 1999; Schmidt and others, 2006). Past studies of Montezuma Well have included physical and chemical analyses of the Well and its waters (Cole and Barry, 1973) and aquatic invertebrates (for example, Blinn and Sanderson 1989). Previous, short-term population studies of the turtles in the Well have been carried out by Rosen (1987) and Malone (1999). 


\section{Field Methods}

We began fieldwork for this project in May 2007. Field studies included two major components: (1) live-trapping of turtles to remove the sliders and to collect biological and ecological data on the mud turtle population; and (2) regular, systematic observations of the activity and behavior of both the mud turtles and the sliders. We used baited hoop traps and basking traps as our primary methods of capturing turtles. Because Montezuma Well has an outlet to nearby Beaver Creek, we also set turtle traps in the creek reach immediately upstream and downstream from the outlet of the Well. We experimented with variations of the basic trapping methods and also tried some additional capture techniques, including direct capture by hand and with dip nets.

This study was conducted in conjunction with efforts by Montezuma Castle National Monument to remove all slider turtles from Montezuma Well. National monument staff received separate funding for the slider removal program, and our work was coordinated with that effort. For this reason, some of the specific objectives of our work were to monitor the success of the removal, and evaluate the effects of removing the sliders on the health of the Montezuma Well system. All slider turtles that were captured were removed from the system. Mud turtles were marked, measured, and assessed for reproductive status, to establish a demographic baseline for the species in Montezuma Well and Beaver Creek. All capture and handling of turtles followed the recommendations for field studies of the American Society of Ichthyologists and Herpetologists (American Society of Ichthyologists and Herpetologists, 2004).

\section{Hoop Traps}

We used baited hoop traps as our main method of catching turtles, both in Montezuma Well and in Beaver Creek. These traps consist of three metal hoops surrounded by coarse-weave netting ( $2.5 \mathrm{~cm}, 1$ inch), with an inward-pointing funnel at one end. Most of the traps we used were $76 \mathrm{~cm}$ (30 in) in diameter by $132 \mathrm{~cm}$ (52 in) long when deployed. We also experimented with larger diameter $(91 \mathrm{~cm} / 36 \mathrm{in})$ funnel traps in an attempt to more effectively catch the larger slider turtles. We deployed from five to ten traps in the Well during each trapping session. A smaller number of traps (two to five) were usually set in Beaver Creek. Placement of these traps was mainly confined to shallow shelves around the edges of the Well, and in shallow backwaters of Beaver Creek, because the top of the trap had to remain above water so that captured turtles could breathe (fig. 1). We deployed some of the hoop traps with floats tied along the sides, so that the traps could be placed in deeper water. We baited traps with sardines or other oily fish, or with canned cat food. We also experimented with fruit bait, again to target sliders. National Park Service staff were an integral part of the trapping effort during many trapping sessions and, in the process, they received training on how to capture and handle turtles.

\section{Basking Traps}

We also used basking traps to capture turtles in the Well. These traps have a floating platform with an attached, open-topped cage that is submerged in the water. Turtles climb up on the platform to bask, drop off of it into the cage, then are unable to climb back out of the cage. The commercial basking trap that we used (Sure-Ketch, Memphis Net and Twine), has a balanced, hinged platform on either end. When the turtle moves toward the center of the trap, the platform tips inward, and the turtle slides off the platform and into the water in the cage. 
We also built an additional basking trap that included a natural, floating ash log that we surrounded with a wire-mesh cage enclosure. The ends of the log protruded beyond the cage portion, so that turtles could climb out of the water onto it. This was a passive trap - turtles that ventured out to the middle of the log would be trapped if they dropped into the water and into the cage. Both basking traps were specifically intended to target sliders because of the propensity of these turtles to come out of the water to bask.

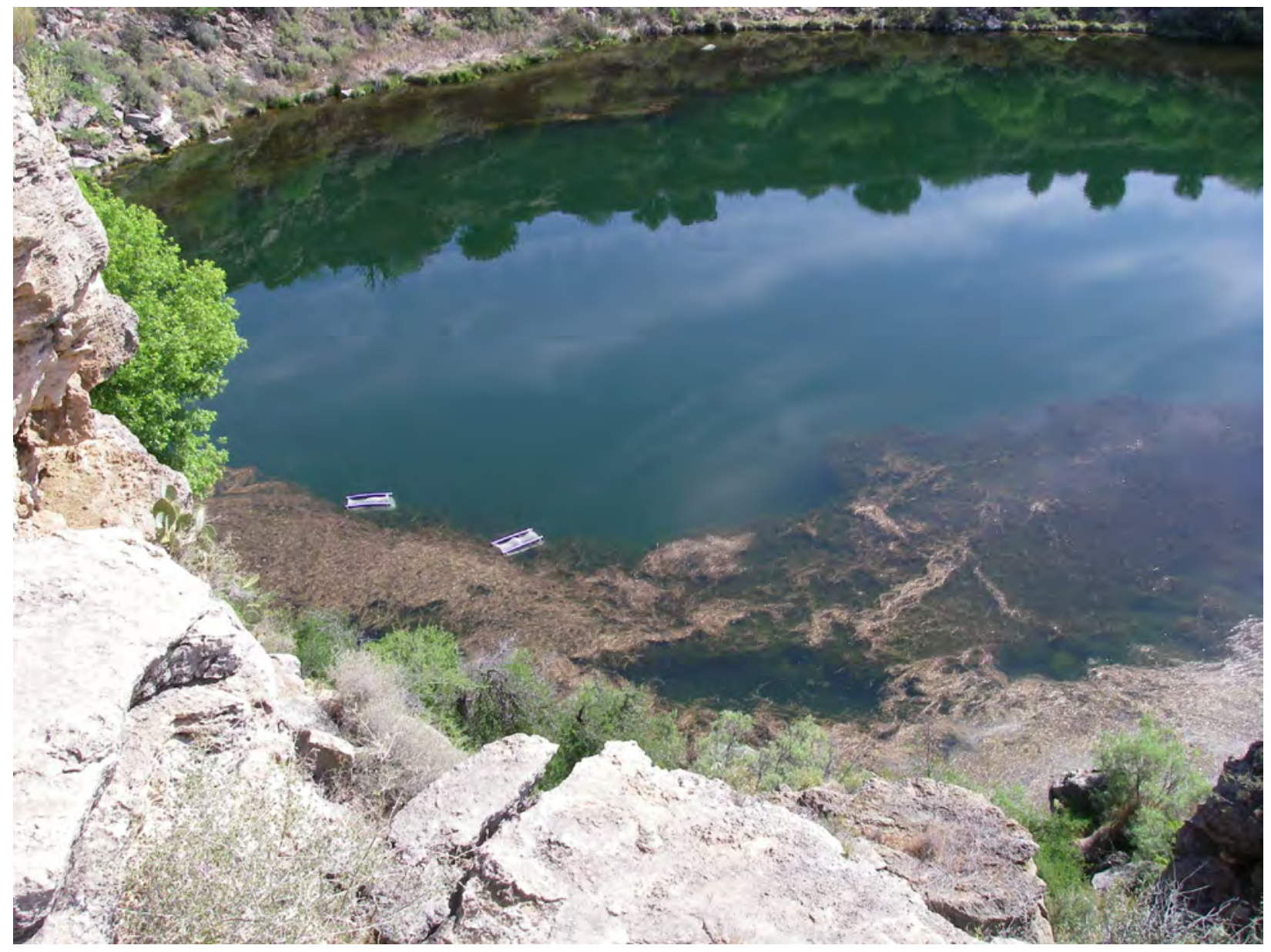

Figure 1. Two hoop traps in place at the edge of aquatic vegetation on the west side of Montezuma Well.

We tried a number of supplemental methods for capturing turtles or for increasing capture rates. These included trammel nets, designed for catching animals swimming in open water. Trammel nets are long, linear nets hanging down from floats at the water's surface, which capture animals by entanglement. Because entanglement could be deep enough that turtles could not reach the surface to breathe, we constantly monitored these nets when they were in place, so captured turtles could be retrieved immediately. We also experimented with pre-baiting of trapping sites, which consisted of placing bait (dry dog food in woven mesh sacks) at specific sites and then setting traps at the sites the following week. The purpose of this pre-baiting was to condition turtles to look for food in these areas and increase subsequent capture rates.

In 2008, we constructed drift fences near the water's edge around different parts of the Well, and placed medium-sized mammal traps (Havahart) and hardware cloth funnel traps 
alongside the fences. The drift fences were low walls of plastic sheeting anchored to wooden stakes, intended to divert the movement of female turtles when they come out of the water to lay eggs. The turtles follow along the fence, where they are directed into the mammal traps or funnel traps (Gibbons and Semlitsch, 1981).

\section{Field Data Collection}

We recorded data on size, weight, health, and reproduction of all turtles captured. Slider turtles were removed from the Well area and donated to the Phoenix Herpetological Society, a private reserve near Phoenix, Arizona, that maintains turtles and other reptiles without risk that the animals will escape back to the wild. We individually marked mud turtles for future recognition, by filing notches in the marginal scutes of the carapace (top shell). We used a letter system for the scutes (fig. 2) and gave each turtle its own unique letter code that typically consisted of three letters from different quadrants of the shell (for example, AIM). We sexed the turtles based on plastron shape and tail size and recorded standard measurements, including carapace length, width, and height, plastron length and width, and weight (Gibbons, 1988; Gibbons, 1990; see appendix 1). We recorded variations of some measurements to allow for direct comparison with the data collected previously by Rosen (1987) and Malone (1999). For example, Rosen measured carapace (shell) width at the widest point, which we recorded as car_wd_max. Malone measured carapace width at the junction of the 4th and 5th marginal scutes, which we recorded as car_wd_45.
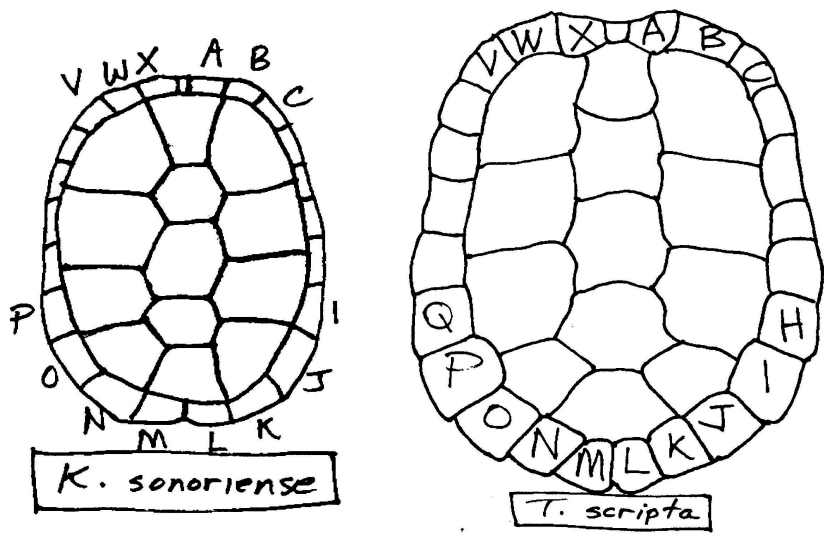

Figure 2. Marking system used to uniquely identify turtles captured at Montezuma Well, Arizona: Sonora mud turtle (K. sonoriense) and red-eared slider (T. scripta).

We estimated the age of individuals, when possible, by counting growth annuli on the scutes of the shell. We also examined each turtle for injuries and outward signs of overall health (for example, skin problems or unusual behavior) and noted other characteristics such as presence and amount of algae on the shell. We took digital photos of most turtles (overhead view of the carapace) for future reference. Slider turtles were handled in the same manner as mud 
turtles, except they were not marked and were removed from the site. For sliders, we also noted degree and pattern of melanism (Gibbons and Lovich, 1990; Lovich and others, 1990).

We palpated females of both mud turtles and sliders for the presence of shelled eggs. All adult females were $\mathrm{x}$-rayed with a portable x-ray machine to visualize shelled eggs. Previous studies have determined that these x-rays do not harm the adult turtles or shelled embryos (Hinton and others, 1997; Lovich and others, 1999). The resulting radiograph images were examined on a light table to check for the presence or absence of eggs. We counted the number of eggs present and measured the width of all eggs in the radiograph image using digital or dial calipers. All x-ray films were retained for later examination, if necessary.

\section{Behavioral Observations}

One of the ways that slider turtles may negatively affect mud turtles is through direct competition for basking space and other resources in the Well. A primary objective of our behavioral observations was to collect data on use of basking sites by mud turtles and sliders, possible competition between the two species, and other interactions between them (Lovich, 1988). We mapped the Well with a grid system to facilitate recording locations where we saw turtles. During standardized observation periods (usually 3-4-hr periods in the morning and afternoon), we continuously monitored turtles from selected points along the rim of the Well. To ensure consistency and comparability of observations, the same person conducted all observations within each year. The observer noted all turtles visible at 15-min intervals and recorded time, species, number, location (sometimes both a descriptive location, as well as a grid cell location), activity, and any interactions between turtles. Weather conditions (air temperature, cloud cover, wind speed, and relative humidity) were recorded at the beginning and end of observations and at hourly intervals during the observations. In addition to providing data on activity and possible competition, these behavioral observations also provided important information on how and where to trap turtles in the Well.

\section{Data Analysis}

All turtle trapping, capture, and observational data were entered into an electronic database. All data sheets were reviewed and checked against the database by a different individual than the person who originally entered the data. The data were also checked and edited using a variety of range tests, indexes for categorical and code fields, and graphical plots of different measurement values to identify outliers. Location data of trap sites and of individual turtles seen during basking observations were entered into a GIS coverage. The GIS also included locations of basking features (rocks and tree branches) and the grid system used to note locations for the behavioral observations (fig. 3).

We calculated summary statistics for size distribution of turtles, weight-to-length ratios (as a measure of the condition of the turtles), mean clutch size of gravid females, and clutch frequency. Clutch frequency was estimated from females captured multiple times during the course of the spring-summer season. Previous studies (Hulse, 1974; Rosen, 1987) have found that successive clutches in Sonora mud turtles are produced approximately 28-30 days apart, and we used this as one of the primary criteria in assessing whether eggs seen in radiographs represented different clutches. When there was a question whether clutches were the same or different, we also noted the number of eggs and their position. 


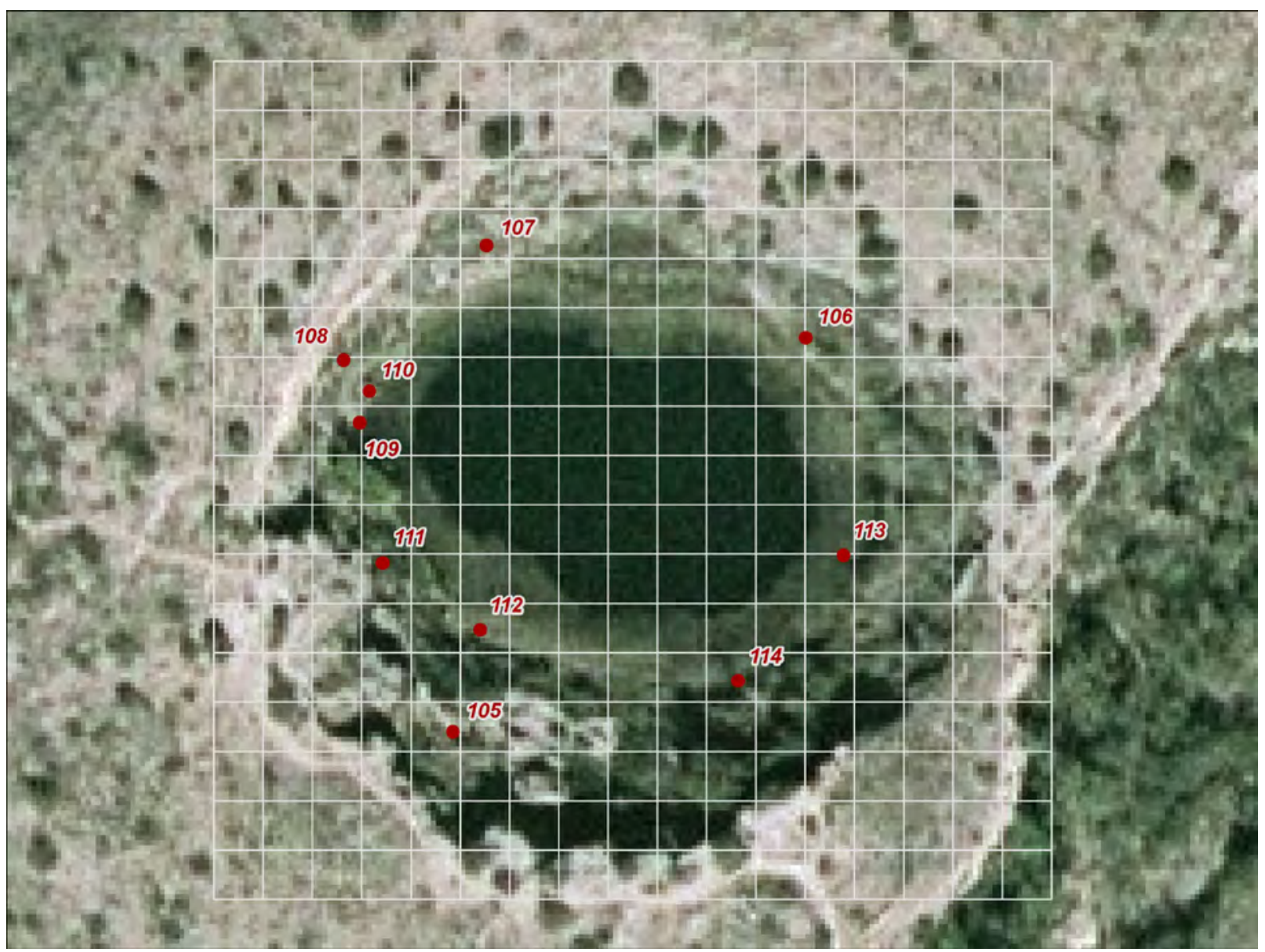

Figure 3. Aerial photo of Montezuma Well, Arizona, showing GIS grid map overlay used to note locations of individual turtles during behavioral observations conducted in 2007 and 2008. Numbered points are basking sites and other recorded reference points.

Unique marking of individual mud turtles allowed us to recognize previously captured individuals and to collect data on growth rate, movements, and longevity. In addition, having marked turtles allowed us to estimate population size, recruitment, and loss rate from the population. Because of the geographically bounded area of the Well and the relatively short time period of our trapping efforts, we used closed-population mark-recapture estimation methods to calculate population size and population characteristics of the mud turtles (program CAPTURE, White and others, 1982). The model selection procedure in CAPTURE evaluates variation in capture probability due to differences among individuals (referred to as heterogeneity), variation over the course of the trapping period (time), and changes in capture probability because of being trapped (behavior, or behavioral response). On the basis of these calculations, CAPTURE selects the best fit population estimator, which is either the null model (Mo, with no variation in capture probability among individuals or over the course of the trapping session) or one of a series of models reflecting heterogeneity (model $\mathrm{Mh}$ ), time variation $(\mathrm{Mt})$, behavioral response $(\mathrm{Mb})$, or a combination of these factors. 


\section{Results}

\section{Field Effort}

We conducted a total of 54 trapping sessions at Montezuma Well and Beaver Creek (table 1). For hoop traps, we had 18 trapping sessions in 2007 totaling 239 trap-days (the number of traps open multiplied by the number of days the traps were operating). Sessions in 2007 spanned from May 1 through October 12. In 2008, we conducted 36 trapping sessions (280 trapdays), spanning from March 31 through September 24. Setting traps, checking traps, and processing turtles during the 2 yr amounted to approximately 900 person-hours of effort.

Table 1. Distribution of turtle trapping effort (using hoop traps) at Montezuma Well, Arizona, in 2007 and 2008. Trap-days denotes the number of traps open during a session multiplied times the number of days the traps were set out.

\begin{tabular}{lcc}
\hline \multicolumn{1}{c}{ Month } & Trap sessions & Trap-days \\
\hline May & 2007 & \\
June & 4 & 34 \\
July & 4 & 50 \\
August & 2 & 20 \\
September & 2 & 27 \\
October & 4 & 72 \\
\hline & 2 & 36 \\
\hline March & 2008 & \\
April & 1 & 8 \\
May & 4 & 38 \\
June & 7 & 58 \\
July & 5 & 33 \\
August & 10 & 74 \\
September & 5 & 37 \\
Total & 4 & 32 \\
\hline
\end{tabular}

Two basking traps were deployed in Montezuma Well in both 2007 and 2008 and were open continuously. In 2007, one commercial basking trap was operated from May 1 to November 8 . We set out a second basking trap of our own design on June 26 and kept it open until November 8. Between these two traps, we had a total of 326 trap-days for basking traps in 2007. In 2008, the commercial basking trap was set out from March 30 through September 24, and a second, large basking trap was constructed and operated from June 30 through September 24 , for a total of 264 basking trap-days.

We conducted a total of 31 behavioral observation sessions, including 22 sessions in 2007 and 9 in 2008. The first session in 2007 was on April 26, and the last was on October 9. All of the 2007 sessions were conducted by Monatesti. In 2008, the first session was on February 29, and the last session was on September 9. The first session in 2008 was conducted by Drost, and the remaining sessions were conducted by Madrak. Total observation time across all sessions was $139 \mathrm{~h}$, with $118 \mathrm{~h}$ in 2007 and $21 \mathrm{~h}$ in 2008. 


\section{Populations}

\section{Turtle Captures}

During 2007 and 2008, we trapped a total of 232 mud turtles (including recaptures) in Montezuma Well and Beaver Creek in hoop traps and basking traps combined. Over the same period, we also captured three turtles by hand and caught two with a dip net. One of the handcaptured turtles was basking on a rock along the shoreline of the Well, and the other two were on land. One of these turtles was a female that appeared to have just finished laying eggs, and the other was a hatchling that we presume was moving between its nest site and the water. In addition to all of these captures, we also found five dead turtles, for a total of 242 encounters of mud turtles by all measures (table 2): 172 of these records were from 2007 and 70 were from 2008.

Not counting recaptures of individuals marked during our study, we encountered 146 individual turtles. Of this number, 24 were turtles that had been marked in earlier studies by Phil Rosen and Matthew Malone, and 119 were new turtles that we marked for the first time. The remaining three turtles were left unmarked. These included one hatchling turtle that was observed, photographed, and released without a mark, and two unmarked turtles that were found dead. Also, on April 1, 2008, an unmarked male was left in a trap for approximately $1 \mathrm{~h}$ but escaped before he was marked or processed. We do not include this turtle in our total number of individuals, because it is possible that he was recaptured and marked at a later date.

We caught 14 nonnative turtles during the same period, including 12 red-eared sliders (fig. 4). Eight of the sliders were captured in 2007 and four in 2008 (table 2). All but one of the sliders was caught in the Well. In 2007, we also captured one Pacific pond turtle. This is the first known record of this species in the State of Arizona. In 2008, we caught a single yellow-bellied slider (Trachemys scripta scripta), a close relative of the red-eared slider native to the Southeastern United States (fig. 4).

Table 2. Total records of Sonora mud turtles (Kinosternon sonoriense) and red-eared sliders (Trachemys scripta) in 2007 and 2008 in Montezuma Well and adjacent Beaver Creek, Arizona. Totals include hand and net captures and turtles found dead.

\begin{tabular}{|c|c|c|c|}
\hline & 2007 & 2008 & Total \\
\hline \multicolumn{4}{|c|}{ Sonora Mud Turtle } \\
\hline Montezuma Well & 143 & 58 & 201 \\
\hline Beaver Creek & 29 & 12 & 41 \\
\hline Total & 172 & 70 & 242 \\
\hline \multicolumn{4}{|c|}{ Red-eared Slider } \\
\hline Montezuma Well & 7 & 4 & 11 \\
\hline Beaver Creek & 1 & 0 & 1 \\
\hline Total & 8 & 4 & 12 \\
\hline
\end{tabular}

Hoop traps accounted for 97 percent of all trap captures of mud turtles over the $2 \mathrm{yr}$ of this study (table 3). Hoop traps also captured more sliders, accounting for 82 percent of trap captures of the small total number for that species. Of the other nonnative turtles, the one Pacific pond turtle was captured in a basking trap, and the yellow-bellied slider was captured in a hoop trap. Other capture methods yielded only small numbers but were important nonetheless for the 
nonnative turtles. A single female slider was captured by hand while she was out of the water to lay eggs on May 25, 2008. Three mud turtles were captured by hand. These included one hatchling found at the top of the steps on the trail leading down to Beaver Creek at the Well outlet (July 27, 2007), one female on land, evidently returning to the water after laying eggs (October 4, 2007), and one adult on a basking rock along the edge of Montezuma Well (April 22, 2008). Two mud turtles were caught using a dip net in 2008.

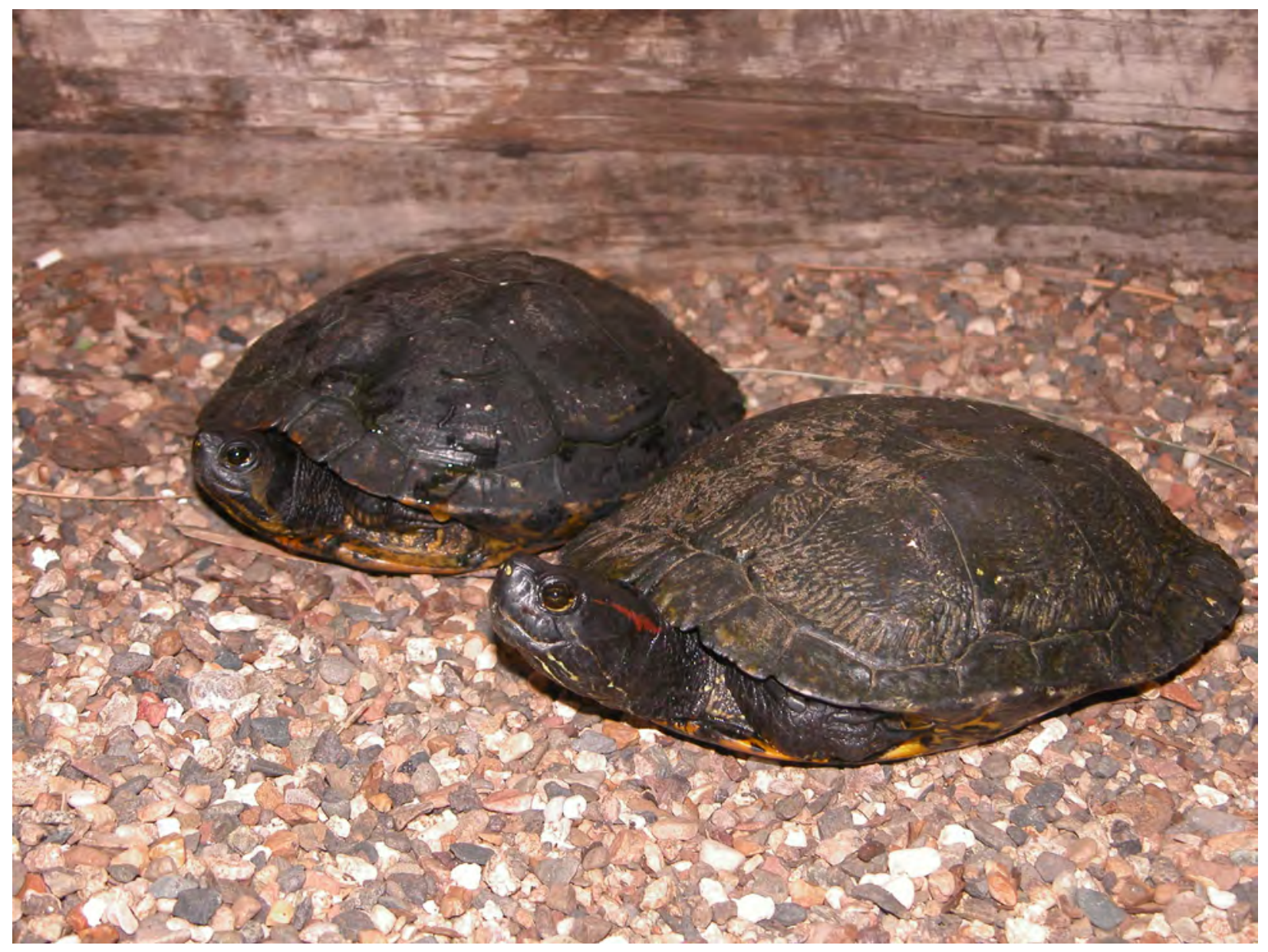

Figure 4. Nonnative turtles from Montezuma Well, 2008. Melanistic male T. scripta elegans in front; male T. scripta scripta in back. 
Table 3. Total captures of Sonora mud turtles (Kinosternon sonoriense) and red-eared sliders (Trachemys scripta) in 2007 and 2008 by trap type, in Montezuma Well and adjacent Beaver Creek, Arizona.

\begin{tabular}{|c|c|c|c|}
\hline & 2007 & 2008 & Total \\
\hline \multicolumn{4}{|c|}{ Sonora Mud Turtle } \\
\hline Hoop Net & 168 & 57 & 225 \\
\hline Basking Trap & 1 & 6 & 7 \\
\hline Total & 169 & 62 & 232 \\
\hline \multicolumn{4}{|c|}{ Red-eared Slider } \\
\hline Hoop Net & 6 & 3 & 9 \\
\hline Basking Trap & 2 & 0 & 2 \\
\hline Total & 8 & 3 & 11 \\
\hline
\end{tabular}

\section{Sex Ratio and Size Structure}

We caught more male turtles than female turtles. Numbers of total individuals of males and females (that is, not counting recaptures) were relatively close in Beaver Creek (table 4) as were total captures of males and females, including all recaptures. In the Well, however, we caught nearly twice as many individual males as females (chi-square $=11.782$ compared to an expected 50:50 ratio, $\mathrm{df}=1, \mathrm{p}=0.0006$ ), and the total number of captures of males was 2.5 times that of females (chi-square $=41.753, \mathrm{df}=1, \mathrm{p}<0.0001$ ). Considering all captures (from Beaver Creek and the Well, combined), there was also a disproportionate number of individual males captured (chi-square $=10.942, \mathrm{df}=1, \mathrm{p}=0.0009$ ), and a disproportionate number of total captures of males (chi-square $=40.382, \mathrm{df}=1, \mathrm{p}<0.0001$ ). The capture rate (taking the total number of captures divided by the number of individuals; for example, 23 total captures of males in Beaver Creek divided by 16 individual males in the creek) was higher for males than for females in Beaver Creek, the Well, and for all captures combined (table 4).

We compared total captures of males and females for the combined (Beaver Creek and Well) data under the null hypothesis that total captures should be directly proportional to the number of individuals caught (that is, no bias toward greater capture totals for males or females, given the total number of individual males and females caught). Total captures of males were significantly different from total captures of females (chi-square $=4.766, \mathrm{df}=1, \mathrm{p}=0.029$ ).

Mud turtles captured in 2007 and 2008 ranged in size up to $149 \mathrm{~mm}$ carapace length (table 5 ). We found a single hatchling mud turtle (carapace length $\approx 26 \mathrm{~mm}$ ) near the top of the bluff above Beaver Creek on July 27, 2007 (fig. 5). The smallest mud turtles captured in hoop traps had carapace lengths of 61 and $63 \mathrm{~mm}$. Within Montezuma Well, captured female turtles were larger, on average, than males (table 5). Their maximum recorded size was also larger. The largest female had a carapace length of nearly $145 \mathrm{~mm}$, and there were 16 females larger than the size of the largest male $(137 \mathrm{~mm})$. In contrast, male and female turtles from Beaver Creek were essentially equal in size, with average carapace length of about $137 \mathrm{~mm}$ and maximum carapace length of $149 \mathrm{~mm}$ for both males and females (table 5). 
Table 4. Sex ratios of Sonora mud turtles from Beaver Creek, Montezuma Well, and overall (Beaver Creek and the Well combined) from captures in 2007 and 2008. Capture rate equals the total number of captures divided by the number of individuals. P-values are from Chi-square tests versus an expected 50: 50 ratio.

[Ratio, number of males: one female; NS, not significant]

\begin{tabular}{lcccc}
\hline & Males & Females & Ratio & p-value \\
\hline \multicolumn{5}{c}{ Beaver Creek } \\
\hline Individuals & 16 & 13 & $1.23: 1$ & NS \\
Total captures & 23 & 16 & $1.44: 1$ & NS \\
Capture rate & 1.44 & 1.23 & & \\
\hline \multicolumn{5}{c}{ Montezuma Well } \\
\hline Individuals & 73 & 37 & $1.97: 1$ & $<0.001$ \\
Total captures & 142 & 52 & $2.73: 1$ & $<0.0001$ \\
Capture rate & 1.95 & 1.41 & \\
\hline \multicolumn{5}{c}{} \\
\hline Individuals & Combined (Beaver Creek and Montezuma Well) & $<0.001$ \\
Total captures & 89 & 50 & $1.78: 1$ & $<0.0001$ \\
Capture rate & 165 & 68 & $2.43: 1$ & \\
\hline
\end{tabular}

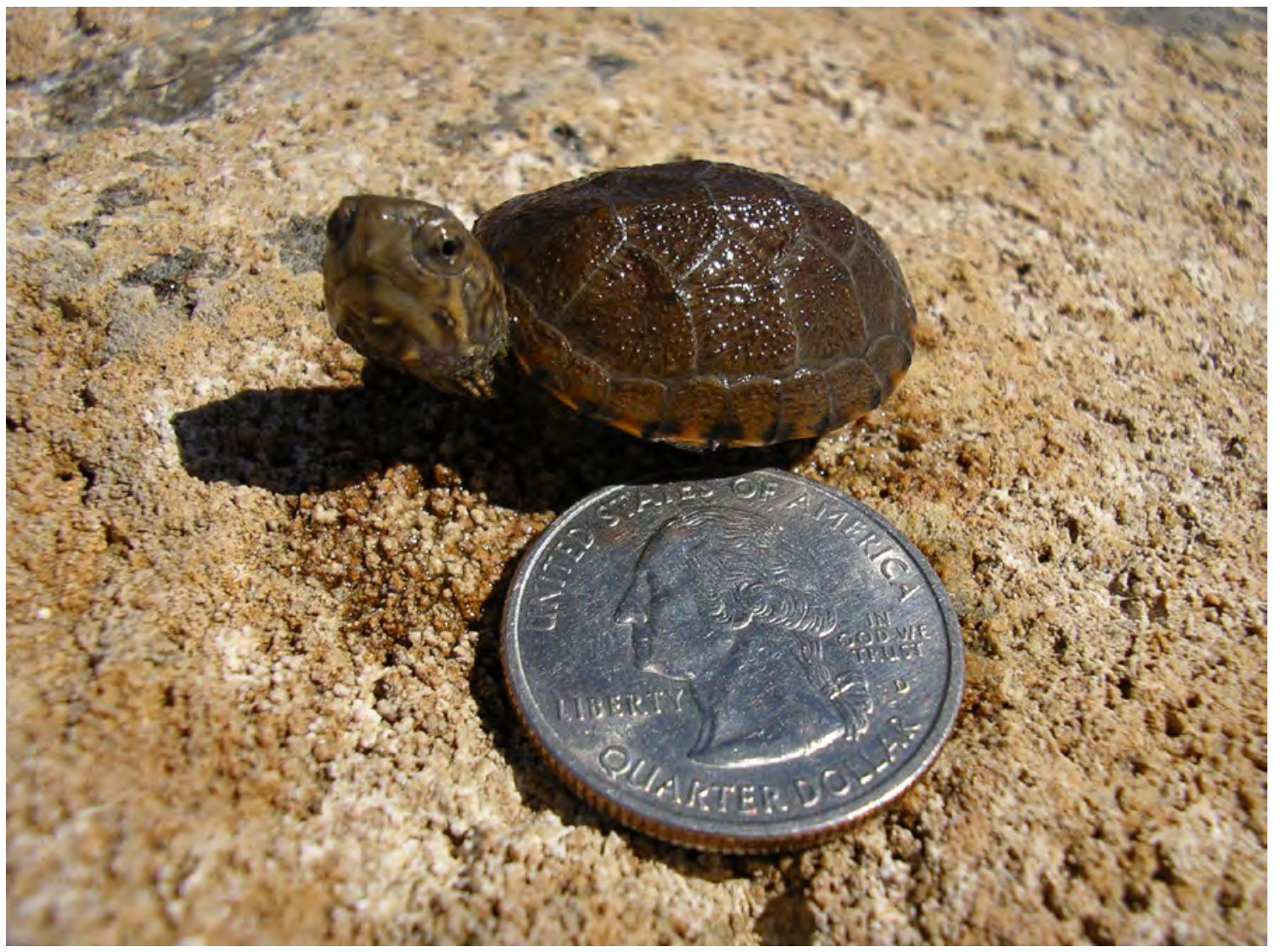

Figure 5. Hatchling mud turtle found along Beaver Creek near Montezuma Well, Arizona, in July 2007. 
Table 5. Carapace length $(\mathrm{mm})$ of Sonora mud turtles trapped in 2007 and 2008 at Beaver Creek and Montezuma Well. Juvenile turtles that we could not sex are not included.

\begin{tabular}{lccccr}
\hline & Minimum & Maximum & Mean & Median & Total (n) \\
\hline \multicolumn{5}{c}{ Montezuma Well } \\
\hline Males & 71.6 & 137 & 124.8 & 128.8 & 131 \\
Females & 85.7 & 144.9 & 133.5 & 135.5 & 52 \\
\hline \multicolumn{5}{c}{ Beaver Creek } \\
\hline Males & 122.6 & 149 & 137.7 & 138 & 21 \\
Females & 129.4 & 149 & 136.9 & 135.5 & 16 \\
\hline
\end{tabular}

We recaptured 22 mud turtles originally marked by Malone (1999) in his study at the Well, which took place 8 yr before the start of our fieldwork. Malone had a unique numbering system that incorporated two notches on individual marginal scutes for higher numbers. These marks were quite distinctive and immediately recognizable. We also caught at least one, and probably two, mud turtles originally marked by Rosen (1987) in his study in 1983. Given their size at first capture, the two turtles originally marked by Rosen would be a minimum of $25 \mathrm{yr}$ old. Because of some overlap in the numbering systems of Rosen and Malone, there is potential confusion about these two latter turtles. When we captured them, both turtles had single notches. One had a notch at scute $\mathrm{O}$ and the other had a notch at scute $\mathrm{P}$, and Rosen and Malone each captured turtles that they marked as "O" and "P." When we captured these turtles, however, the notches appeared old; they were shallow, rounded, and not nearly as sharp and distinct as the marks on the many turtles that we knew to be from Malone's study.

Nearly all of the sliders captured were large individuals (table 6). The only slider smaller than $174 \mathrm{~mm}$ was an individual of undetermined sex measuring $128 \mathrm{~mm}$. This individual was also the only slider caught in Beaver Creek. The lone Pacific pond turtle caught in Montezuma Well was relatively small, and the lone yellow-bellied slider was a medium-sized adult (table 6). 
Table 6. Captures of nonnative turtles at Montezuma Well, Arizona, including species, sex, carapace length, and weight.

[TRSC, red-eared slider; ACMA, Pacific pond turtle; SCSC, yellow-bellied slider; Car. Ln., straight-line carapace length, in $\mathrm{mm}]$

\begin{tabular}{llrcrr}
\hline Species & \multicolumn{1}{c}{ Location } & Date & Sex & $\begin{array}{c}\text { Car. Ln. } \\
(\mathbf{m m})\end{array}$ & $\begin{array}{c}\text { Weight } \\
\text { (g) }\end{array}$ \\
\hline TRSC & Montezuma Well & $5 / 1 / 2007$ & $\mathrm{M}$ & 176 & 850 \\
TRSC & Montezuma Well & $5 / 1 / 2007$ & $\mathrm{M}$ & 211 & 1,650 \\
TRSC & Montezuma Well & $5 / 1 / 2007$ & $\mathrm{~F}$ & 237 & 1,865 \\
TRSC & Montezuma Well & $5 / 16 / 2007$ & $\mathrm{~F}$ & 237 & 1,770 \\
TRSC & Montezuma Well & $5 / 22 / 2007$ & $\mathrm{M}$ & 217 & 1,250 \\
TRSC & Montezuma Well & $6 / 12 / 2007$ & $\mathrm{~F}$ & 204 & 1,010 \\
TRSC & Montezuma Well & $8 / 3 / 2007$ & $\mathrm{M}$ & 211 & 1,030 \\
ACMA & Montezuma Well & $9 / 10 / 2007$ & $\mathrm{M}$ & 109 & 238 \\
TRSC & Beaver Creek & $9 / 28 / 2007$ & $\mathrm{U}$ & 128 & 342 \\
TRSC & Montezuma Well & $5 / 6 / 2008$ & $\mathrm{M}$ & 200 & 1,000 \\
TRSC & Montezuma Well & $5 / 25 / 2008$ & $\mathrm{~F}$ & 209 & 1,320 \\
SCSC & Montezuma Well & $6 / 10 / 2008$ & $\mathrm{M}$ & 174 & 990 \\
TRSC & Montezuma Well & $6 / 10 / 2008$ & $\mathrm{~F}$ & 186 & 995 \\
TRSC & Montezuma Well & $7 / 16 / 2008$ & $\mathrm{M}$ & 221 & 1,345 \\
\hline
\end{tabular}

\section{Turtle Numbers}

Capture rate (number of turtles caught divided by number of trap-days) provides a simple, relative measure of turtle abundance and a method of comparing turtle numbers between different trapping studies. During his study in June-August 1983, Rosen (1987) caught between 19 and 40 Sonora mud turtles per 10 trap-days (fig. 6). Malone (1999) studied turtle populations at Montezuma Well for a senior thesis project at Embry-Riddle Aeronautical University in Prescott, Arizona, in 1999. His capture rates from late July through early November ranged from 2 to 25 mud turtles per 10 trap-days (fig. 7). We trapped from the beginning of May to early October in 2007 and from the end of March to mid-September in 2008. Considering just Montezuma Well trapping, our capture rates ranged from 2 to 31 per 10 trap-days in 2007 and 0 to 7 in 2008 (figs. 8 and 9, respectively).

Trapping sessions for the three studies spanned different parts of the active season for mud turtles at Montezuma Well. Rosen's study spanned most of the summer, from late June through mid-August 1983. Malone's study (1999) began in late July and continued into early November. Our trapping extended from early to late spring into the fall of both 2007 and 2008. Turtle activity (as measured by capture rates) varied over the course of the seasons (see figs. 79), so we calculated monthly average trap success from 1983, 1999, and from 2007 and 2008 to facilitate comparison across years (fig. 10). Particularly during the part of the year when all three studies overlapped, mud turtle capture rates declined substantially from 1983 to 1999, were generally lower still in 2007, and declined even further in 2008. The low capture rates throughout 2008 are particularly striking. 
As expected (since we removed all individuals captured), capture rates of sliders have declined substantially since the first month of trapping in 2007. In May 2007, we caught five sliders. The most nonnative turtles we caught in any month after that was two, and no nonnative turtles were caught in July and October 2007, nor in April, August, and September 2008.

Similarly, we saw far fewer nonnative turtles during our systematic observations in 2008. By the latter half of July and August 2008, basking observations could only account for a total of three sliders. All three of these individuals (one female, one male, and a small individual of unknown sex) were distinctive in size and coloration. The male had a distinct, dark, subterminal crescent on the posterior half of his shell, and he had visibly long claws on his front feet. The female had relatively bright yellow radial lines extending outward from the midline of her carapace and visible red ear-stripes. The smaller individual had yellow highlights on the marginal scutes ringing its carapace, vibrant red "ears," and a noticeably lighter (compared to the two larger turtles) olive-green/gray carapace. In the last four basking observation sessions, we did not see any sliders except for these three individuals.

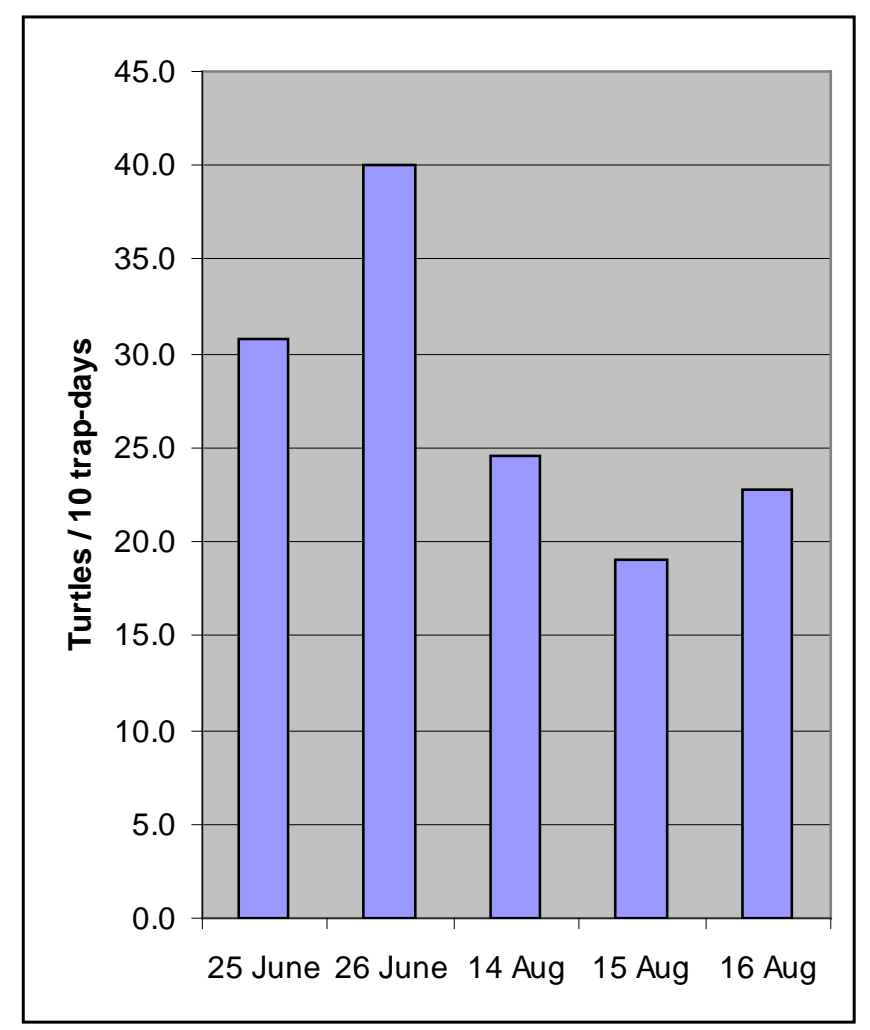

Figure 6. Capture rates of mud turtles at Montezuma Well, Arizona, in June-August 1983 (Rosen 1987). 


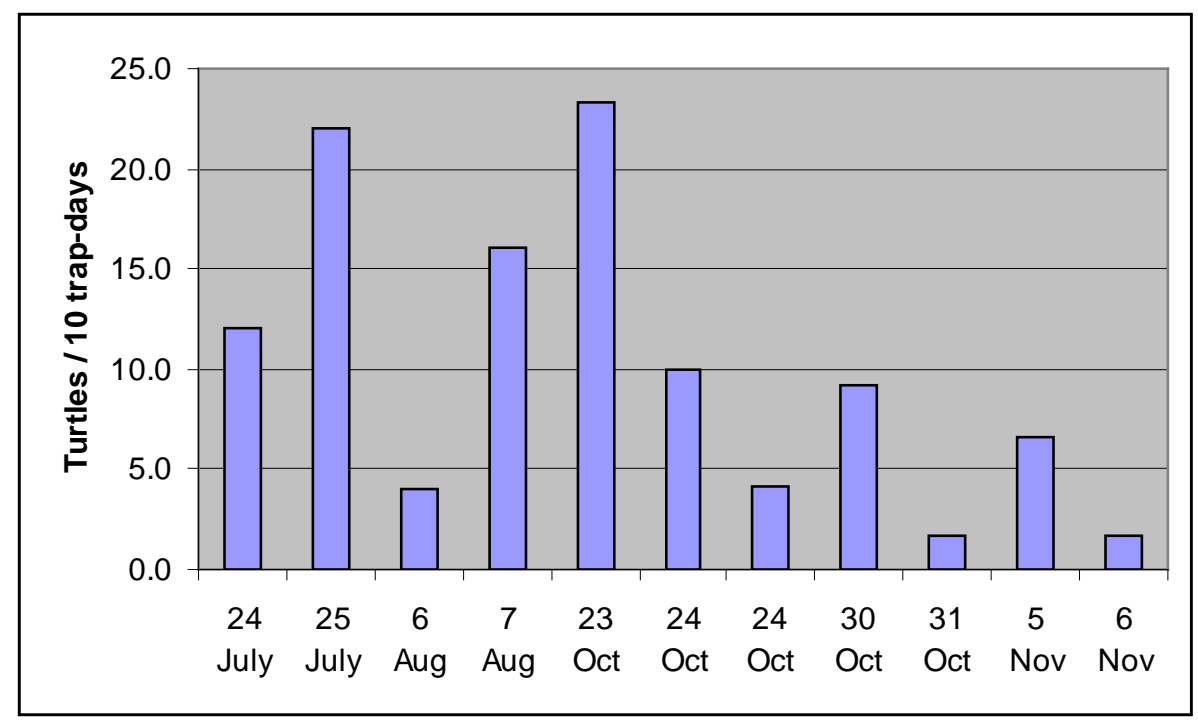

Figure 7. Capture rates of mud turtles at Montezuma Well, Arizona, in July-November 1999 (Malone 1999).

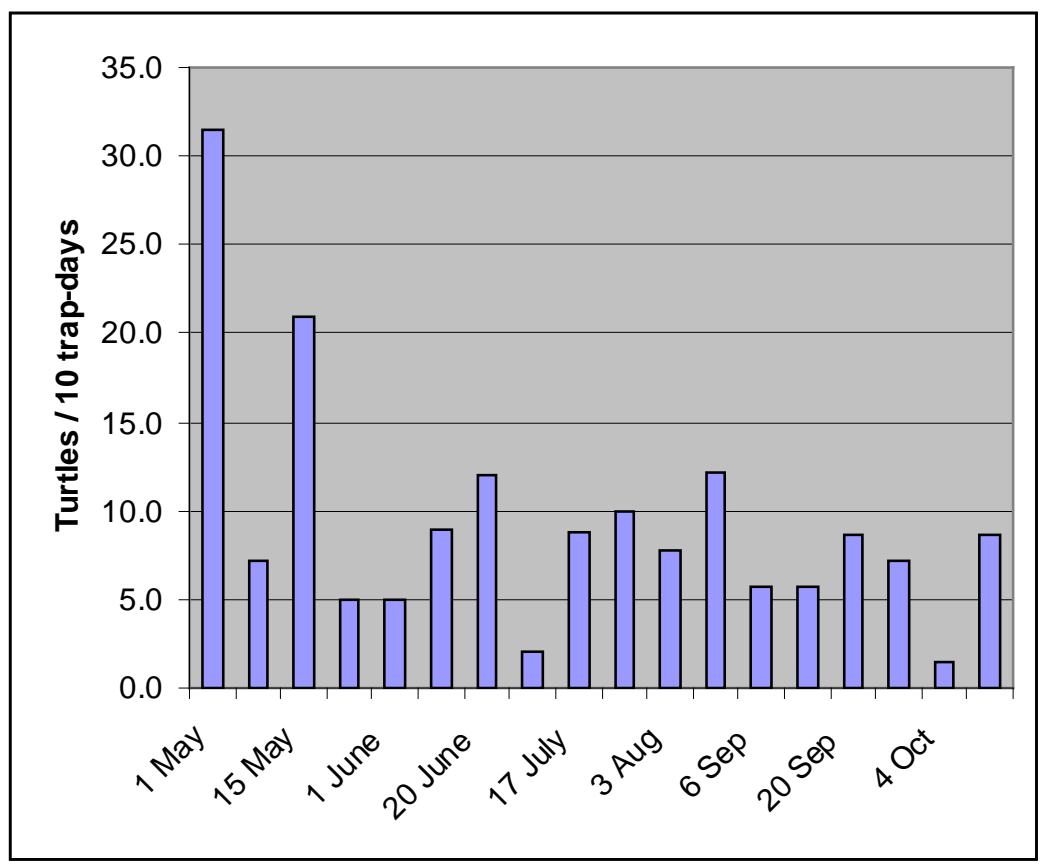

Figure 8. Capture rates of mud turtles at Montezuma Well, Arizona, in May-October 2007. 


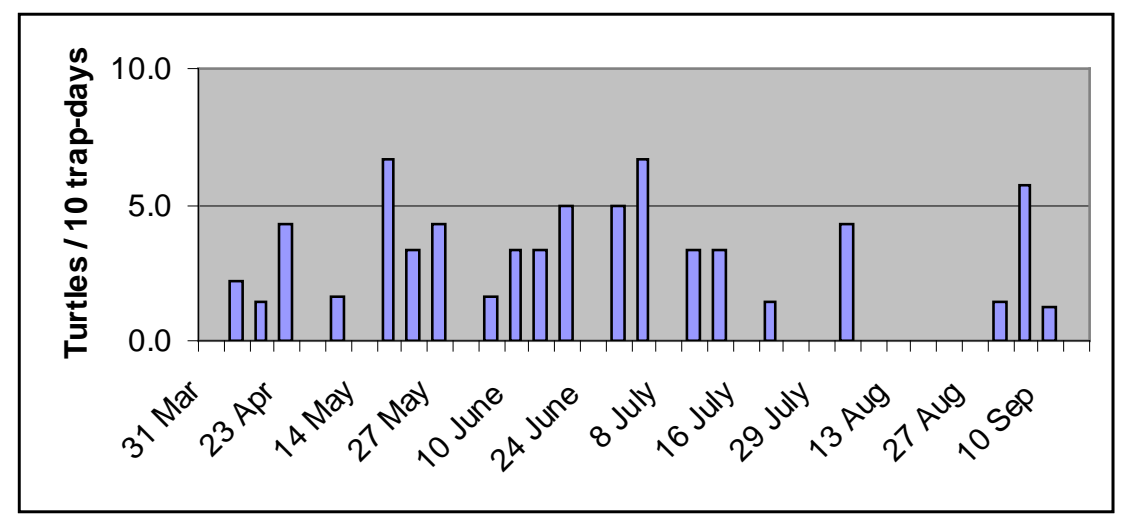

Figure 9. Capture rates of mud turtles at Montezuma Well, Arizona, in March-September 2008.

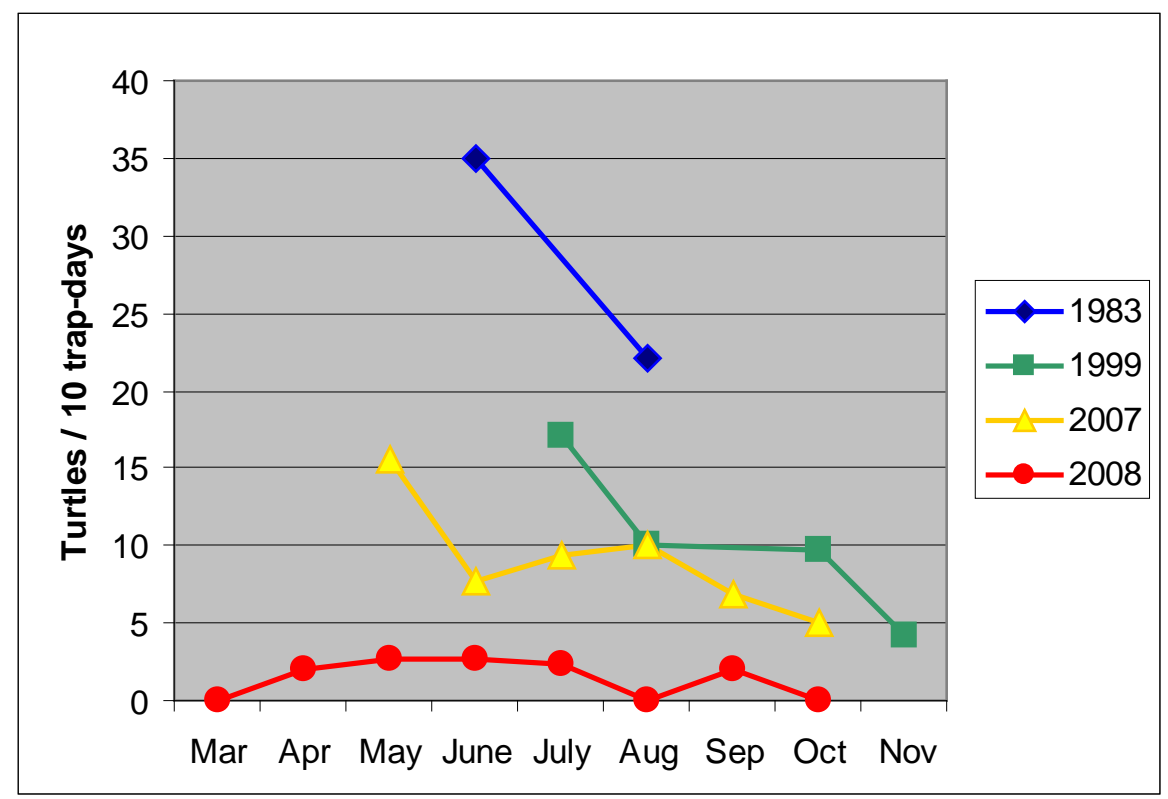

Figure 10. Comparison of capture rates of Sonora mud turtles at Montezuma Well during three trapping studies: Rosen (1987; fieldwork in 1983), Malone (1999), and this study (2007 and 2008).

In addition to simple capture rates, we used mark-recapture models to estimate the population size of mud turtles in Montezuma Well (table 7). The model selection procedure in program CAPTURE calculates criteria values for different population estimators, reflecting variation in capture probabilities in the data. The model with the highest criteria value (up to a maximum of 1) is the best fit model. For the 2007 data, models incorporating time variation in capture probabilities, individual heterogeneity, and behavioral response (models Mth and Mtb) provided the best available models. In 2008, the null model (Mo) and heterogeneity model (Mh) provided the best fit. 
Table 7. Population estimates ( \pm standard error) for Sonora mud turtles in Montezuma Well, Arizona, in 2007 and 2008. See text for explanation of models and model selection calculation.

\begin{tabular}{ccc}
\hline Model & Criteria value & Population estimate \\
\hline \multicolumn{3}{c}{2007} \\
\hline Mo & 0.37 & $160 \pm 17.1$ \\
Mth & 0.90 & $218 \pm 38.4$ \\
Mtb & 0.99 & $153 \pm 78.7$ \\
\hline \multicolumn{3}{|c}{} \\
\hline Mo & 1.00 & $98 \pm 25.9$ \\
Mh & 1.00 & $169 \pm 41.9$ \\
\hline
\end{tabular}

We compared our estimates for 2007 and 2008 to population estimates from Rosen's 1983 trapping study and Malone's 1999 study, based on calculations presented in Malone (1999). The Peterson, Schnabel Binomial, and Schumacher estimators calculated by Malone do not allow for variation in capture probabilities, so they are closest to the null model in CAPTURE (table 8). As with the capture rate calculations, the population estimates from 1983 to 1999 to 2007 and 2008 show a substantial decline in estimated numbers of mud turtles at Montezuma Well over this time span.

Table 8. Comparison of population estimates for Sonora mud turtles at Montezuma Well from studies by Rosen (1983), Malone (1999), and this study $(2007,2008)$. Estimators are the models used to calculate population size (see text).

\begin{tabular}{lclc}
\hline \multicolumn{1}{c}{ Study } & Year & Estimator & $\begin{array}{c}\text { Population } \\
\text { estimate }\end{array}$ \\
\hline Rosen & 1983 & Schnabel & 327 \\
& & Schumacher & 346 \\
Malone & \multirow{2}{*}{1999} & Schnabel & 178 \\
& & Schumacher & 162 \\
This study & 2007 & null/Mo & 160 \\
& 2008 & null/Mo & 98 \\
\hline
\end{tabular}

\section{Injuries and Mortality}

We recorded a variety of injuries on the turtles trapped in Montezuma Well and Beaver Creek (table 9). These injuries included cuts and abrasions to the skin of the head, legs, and body; injury to one or both eyes, typically with the eye being closed and sometimes sunken and evidently non-functional; cracks or cuts in the horny jaws of the turtle; broken or missing claws; and damage to the shell, ranging from small chips or pits in the shell surface, to deep cracks or portions of the shell being broken off (such as one or more of the marginal scutes, forming the rim of the shell). A small category of "other" includes injuries that do not fit in the preceding categories, such as a portion of the turtle's skin separated from the bony shell. Turtles less than 
$100 \mathrm{~mm}$ carapace length had no observed injuries, while number of injuries generally increased with size in larger size classes of turtles.

None of the injuries that we recorded appeared to be life threatening. However, some injuries must have had a significant impact on the life of the individual. Some shell damage involved deep cracks affecting a large portion of the shell and presumably required significant energy to heal. Most eye injuries appeared to have resulted in blindness in one eye, and one individual (an adult female, code CKV) was blind in both eyes. Blindness in one or both eyes was associated with capture probability. There were nine turtles with injuries to one or both eyes, and these nine individuals were captured a total of 29 times (average of 3.22 captures per individual). There were 98 turtles with no recorded eye injuries, and these individuals were caught a total of 154 times (average of 1.57 captures per individual). Compared to an expectation that turtles with and turtles without eye injuries should be caught at the same rate relative to their numbers, these capture totals were significantly different (chi-square $=13.11, \mathrm{df}=1, \mathrm{p}=0.0003$ ).

Over the 2-yr span of this study, we found five mud turtles that had recently died. We found one recently dead mud turtle in 2007 and four in 2008. The five dead turtles included one juvenile, two females, and two males, and they ranged in size from $81.6 \mathrm{~mm}$ (the juvenile) to $126.5 \mathrm{~mm}$ in carapace length. There was no indication of cause of death for four of the turtles. The fifth mortality was a previously captured female (code BKN, $126.5 \mathrm{~mm}$ in length) that consisted of carapace and plastron with a line of clear puncture marks on the carapace, which appeared to be from a mammalian carnivore.

Table 9. Injuries in Sonora mud turtles, in relation to size class. See text for explanation of different injury types.

[n, number of individuals in each size class; \# with injuries, number of individuals with one or more injuries; Total, total number of injuries in size class; \% with injuries, number of individuals with one or more injuries, divided by the number of individuals in the size class]

\begin{tabular}{|c|c|c|c|c|c|c|c|c|c|c|}
\hline $\begin{array}{l}\text { Size class } \\
(\mathrm{mm})\end{array}$ & $\mathrm{n}$ & $\begin{array}{l}\text { \# with } \\
\text { injuries }\end{array}$ & Cuts & Eye & Shell & Jaw & Claws & Other & Total & $\begin{array}{l}\text { \% with } \\
\text { injuries }\end{array}$ \\
\hline$<=60$ & 1 & 0 & & & & & & & 0 & 0 \\
\hline $60.1-70$ & 3 & 0 & & & & & & & 0 & 0 \\
\hline $70.1-80$ & 2 & 0 & & & & & & & 0 & 0 \\
\hline $80.1-90$ & 4 & 0 & & & & & & & 0 & 0 \\
\hline $90.1-100$ & 3 & 0 & & & & & & & 0 & 0 \\
\hline $100.1-110$ & 7 & 1 & & 1 & & & & & 1 & 14 \\
\hline $110.1-120$ & 16 & 1 & & 1 & & & 1 & & 2 & 6 \\
\hline $120.1-130$ & 43 & 14 & 1 & & 12 & & 3 & 1 & 17 & 33 \\
\hline $130.1-140$ & 59 & 17 & 1 & 7 & 9 & 2 & 4 & & 23 & 29 \\
\hline $140.1-150$ & 16 & 7 & & 1 & 6 & & & 3 & 10 & 44 \\
\hline
\end{tabular}

\section{Reproduction}

Field x-rays of female turtles provided our primary means of measuring reproductive activity (fig. 11). We found female Sonora mud turtles with shelled eggs as early as April 23 (2008; the earliest period in which we caught adult females) and as late as September 28, (2007). We x-rayed only four female turtles after September 28 (two on October 4 and two on October 12) and none of them had eggs, so we excluded October captures from the calculations. We calculated the percentage of females that had eggs at the time of capture, including those adult 
female turtles ( $>115 \mathrm{~mm}$ carapace length) that were captured and x-rayed between April 23 and September 28 (table 10). The proportion of females that were gravid was marginally lower in 2008 compared to 2007, but this difference was not significant (Fisher's exact test, $\mathrm{p}=0.6453$ for both Beaver Creek and Montezuma Well combined, $p=1.000$ for just Montezuma Well). Overall (both years combined), the proportion of females gravid in Beaver Creek (53.3 percent) was nearly identical to the proportion that were gravid in Montezuma Well (54.3 percent).

The preceding calculations include all x-rays of all females that were captured, so it includes some individuals more than once, when they were captured multiple times in the same year. Likewise, it includes more than one clutch for some females (or the same clutch recorded more than once, if the individual was captured on closely consecutive dates). Just considering annual reproductive status of individual females, we caught 36 different females between April and September of 2007, and 21 of those individuals (58.3 percent) were known to have produced eggs sometime during the year. Between April and September 2008, we caught 14 individual females, and 5 of those individuals ( 35.7 percent) were shown by $\mathrm{x}$-ray to have been gravid during 2008.

We recorded few instances of females producing more than one clutch in the same year (table 11). Only one female (ANW in 2007) is known to have produced more than one clutch, as evidenced by different numbers of eggs in radiographs taken at least 28 days apart. Turtle CJKV had six eggs on June 17 and five eggs on July 15 and July 30 in 2008, so she also appeared at first to have had more than one clutch. However, close examination of the radiograph showed that the five eggs on the latter two dates were in the same location and same orientation as five of the eggs present on June 17. We consider this correspondence in location and orientation to be extremely unlikely, if these eggs represented separate clutches. Although it has not previously been reported in the literature for Sonora mud turtles, this female evidently laid one of her eggs on 17 June and retained the other five through at least the end of July. 


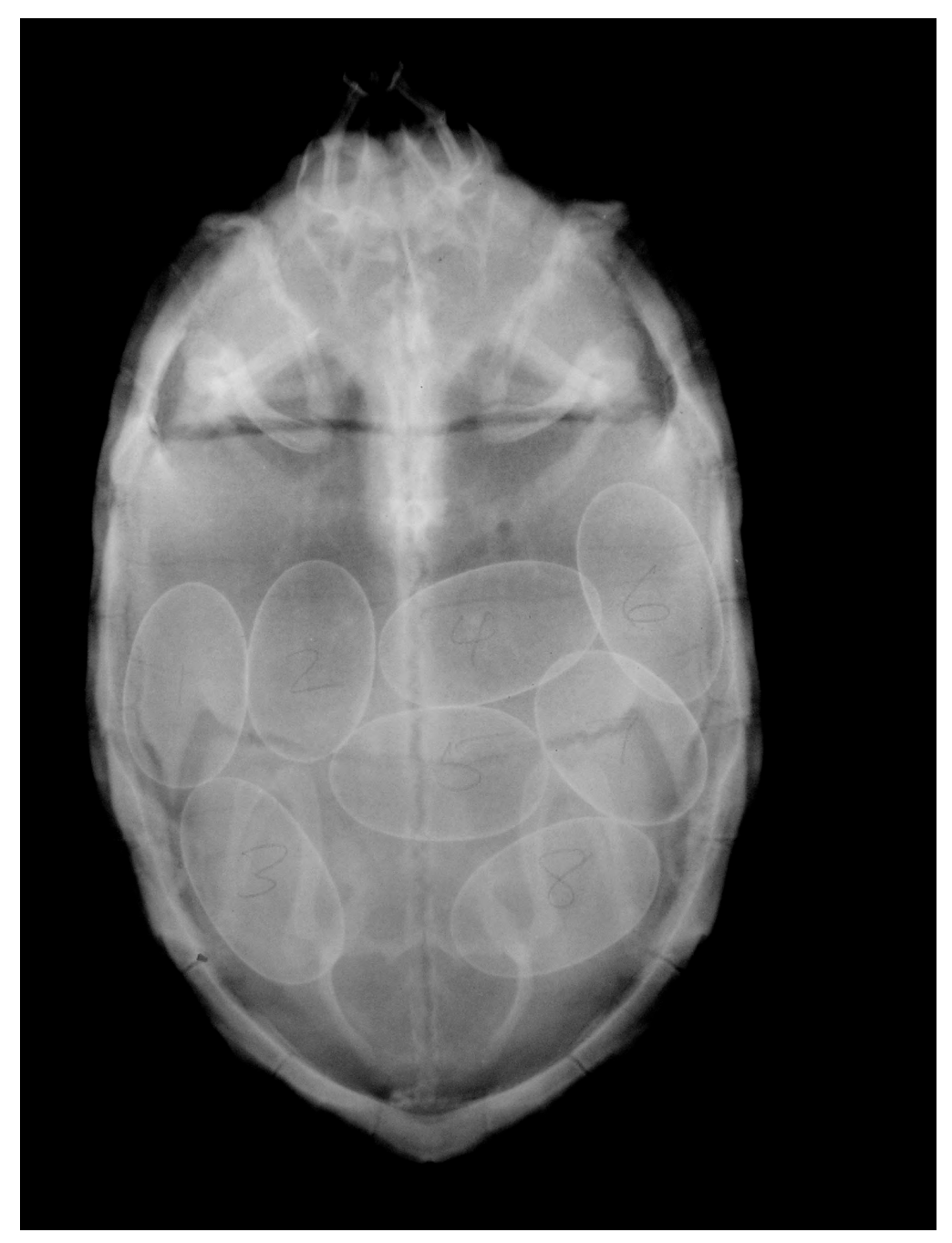

Figure 11. Radiograph showing female Sonora mud turtle with eight eggs.

Table 10. Numbers and percent of female Sonora mud turtles found to be gravid at Montezuma Well and adjacent Beaver Creek, Arizona, in 2007 and 2008. Data are for female turtles greater than $115 \mathrm{~mm}$ carapace length $\mathrm{x}$-rayed between late April and late September.

\begin{tabular}{|c|c|c|c|}
\hline & Number & Gravid & $\%$ gravid \\
\hline \multicolumn{4}{|c|}{2007} \\
\hline Beaver Creek & 11 & 6 & 54.5 \\
\hline Montezuma Well & 31 & 16 & 51.6 \\
\hline Total & 42 & 22 & 52.4 \\
\hline \multicolumn{4}{|c|}{2008} \\
\hline Beaver Creek & 4 & 1 & 25.0 \\
\hline Montezuma Well & 15 & 8 & 53.3 \\
\hline Total & 19 & 9 & 47.4 \\
\hline
\end{tabular}


Table 11. Detailed reproductive history of female Sonora mud turtles captured multiple times in 2007 and 2008 at Montezuma Well and adjacent Beaver Creek, Arizona.

[Code, identifying mark of each female; carapace, straight-line carapace length, in mm; eggs, number of eggs at each capture date in 2007 and 2008; dates, capture dates for this individual in 2007 and 2008]

\begin{tabular}{llllll}
\hline \multicolumn{1}{c}{ Code } & $\begin{array}{c}\text { Carapace } \\
(\mathbf{m m})\end{array}$ & $\begin{array}{c}\text { Eggs } \\
\mathbf{2 0 0 7}\end{array}$ & \multicolumn{1}{c}{$\begin{array}{c}\text { Dates } \\
\mathbf{2 0 0 7}\end{array}$} & $\begin{array}{c}\text { Eggs } \\
\mathbf{2 0 0 8}\end{array}$ & \multicolumn{1}{c}{$\begin{array}{c}\text { Dates } \\
\mathbf{2 0 0 8}\end{array}$} \\
\hline 2AM & 139 & $0-0-0$ & May 15, June 20, October 4 & & \\
2BINU & 138.4 & $0-0$ & May 1, August 14 & & \\
2CV & 142 & 7 & May 15 & $6-6-6$ & July 9, July 22, July 30 \\
AKX & 130.5 & $6-0$ & May 15, September 20 & & \\
ALW & 136 & $0-7$ & May 15, September 6 & 0 & July 3 \\
ANW & 129.5 & $5-3$ & June 6, July 27 & & \\
BIX & 141 & 1 & July 17 & 0 & July 29 \\
BJM & 149 & 8 & July 17 & 0 & July 22 \\
CJKV & 136.6 & & & $6-5-5$ & June 17, July 15, July 30 \\
CLW & 142 & & & $0-0$ & July 15, September 9 \\
\hline
\end{tabular}

We captured four individual females in both 2007 and 2008. Of these, only one was known to have produced eggs in 2007 and 2008. Turtle 2CV was recorded with seven eggs in 2007 and six eggs in 2008. The other turtles (ALW, BIX, and BJM) were only recorded with eggs in 2007, but all three were only caught a single time in 2008.

We have only scattered observations relating to egg-laying and hatching times, but they indicate a broad seasonal span for egg laying by mud turtles at the Well. Observations of nesting mud turtles include the following:

- May 24, 2008 - Turtle out of water, at end of trail past swallet in late morning (report by visitor, location approximately $431172 \mathrm{E}, 3834150 \mathrm{~N}, \mathrm{NAD} 83$ )

- July 22, 2009-Adult turtle out of water on south side of the Well, crossing trail in direction of the Well

- 27 July 2007-Hatchling turtle (carapace length $26 \mathrm{~mm}$ ) found by Monatesti at top of steps on trail down to Beaver Creek

- 24 Sept 2007- "Visitor reported a turtle digging by the steps leading down into the Well" (identified as mud turtle)

- 4 Oct 2007-Monatesti and Drost found adult female CJN near bottom of trail into the Well, by lower steps. Turtle was heading downhill and appeared to already have dug nest (dirt was caked on posterior carapace and on tail, hind feet, and front claws). She was x-rayed and did not have any shelled eggs

We recorded only one slider nesting during our study, but females had previously been noted out of the water by NPS staff. Observations of egg-laying of sliders include the following:

- May 25, 2008 - NPS staff found large female along trail, about halfway down trail into the Well, at rock bluff. This turtle was captured and held overnight. She laid one egg between May 25 and 26, which was broken when she was checked the next morning

- Date not recorded, 1999 or 2000-NPS volunteer Don Montgomery observed a slider laying eggs along the upper part of the trail down into the Well, at the rock face, "8 or 9 years ago." He watched her lay 14 eggs (oral commun., May 26, 2008). 


\section{Behavioral Observations}

We conducted 31 sessions of behavioral observations, totaling nearly $140 \mathrm{~h}$ of observations. Monatesti carried out a total of 22 observation sessions in 2007 (118.3 h), from April 26 to October 9. Observations in 2008 were by Madrak (plus one early session by Drost), totaling nine sessions $(20.8 \mathrm{~h}$ ) from February 29 to September 9. For all sessions combined, we recorded a total of 1,667 records of turtle observations in Montezuma Well. These included 411 observations of mud turtles and 1,256 of sliders (table 12). The number of observations of sliders was much higher than observations of mud turtles, particularly in relation to the much lower numbers of sliders in the Well. This follows from the well-developed basking habit of sliders (Auth, 1975) in comparison with non-emydid turtles like $K$. sonoriense. Also, even taking into account the lower observation effort in 2008, the numbers of observations of both species were much fewer in 2008.

Observations were categorized as swimming, aquatic basking (turtles floating at the surface to warm up), aerial basking (turtles out of the water on rocks or logs or on top of aquatic vegetation), and other activity. Individual basking locations were noted, along with any interactions between different turtles. Aerial basking sites are relatively few in the Well, and individual sites received repeated use. However, the sites were usually segregated by species (that is, sliders and mud turtles were not seen basking in proximity to each other).

Activity (measured as number of observations of turtles per hour) varied both seasonally and by time of day (fig. 12). Sliders were conspicuously more active in the spring (April and May), with activity declining in June. Activity remained low through the remainder of the summer and fall, except for an apparent increase in September. Mud turtle activity was highest in April, with a secondary peak in July and August. The peak of daily activity for sliders was in the middle of the day (usually in the 11 a.m. to 12 noon hour). In contrast, mud turtles showed peak activity in mid-morning (9-10 a.m.), with a secondary peak in mid- to late afternoon in the late summer and early fall. Activity was consistently low in the middle of the day.

Table 12. Summary of basking observations for Sonora mud turtles and red-eared sliders at Montezuma Well, Arizona, in 2007 and 2008. Observation periods were late April through early October in 2007 and the end of February through early September in 2008 (see text).

\begin{tabular}{|c|c|c|c|}
\hline & 2007 & 2008 & Total \\
\hline Mud turtle & 373 & 38 & 411 \\
\hline Slider - unknown sex & 962 & 45 & 1,007 \\
\hline Slider - male & 174 & 37 & 211 \\
\hline Slider - female & 20 & 18 & 38 \\
\hline Total Sliders & 1,156 & 100 & 1,256 \\
\hline
\end{tabular}


Basking Turtles-April 2007

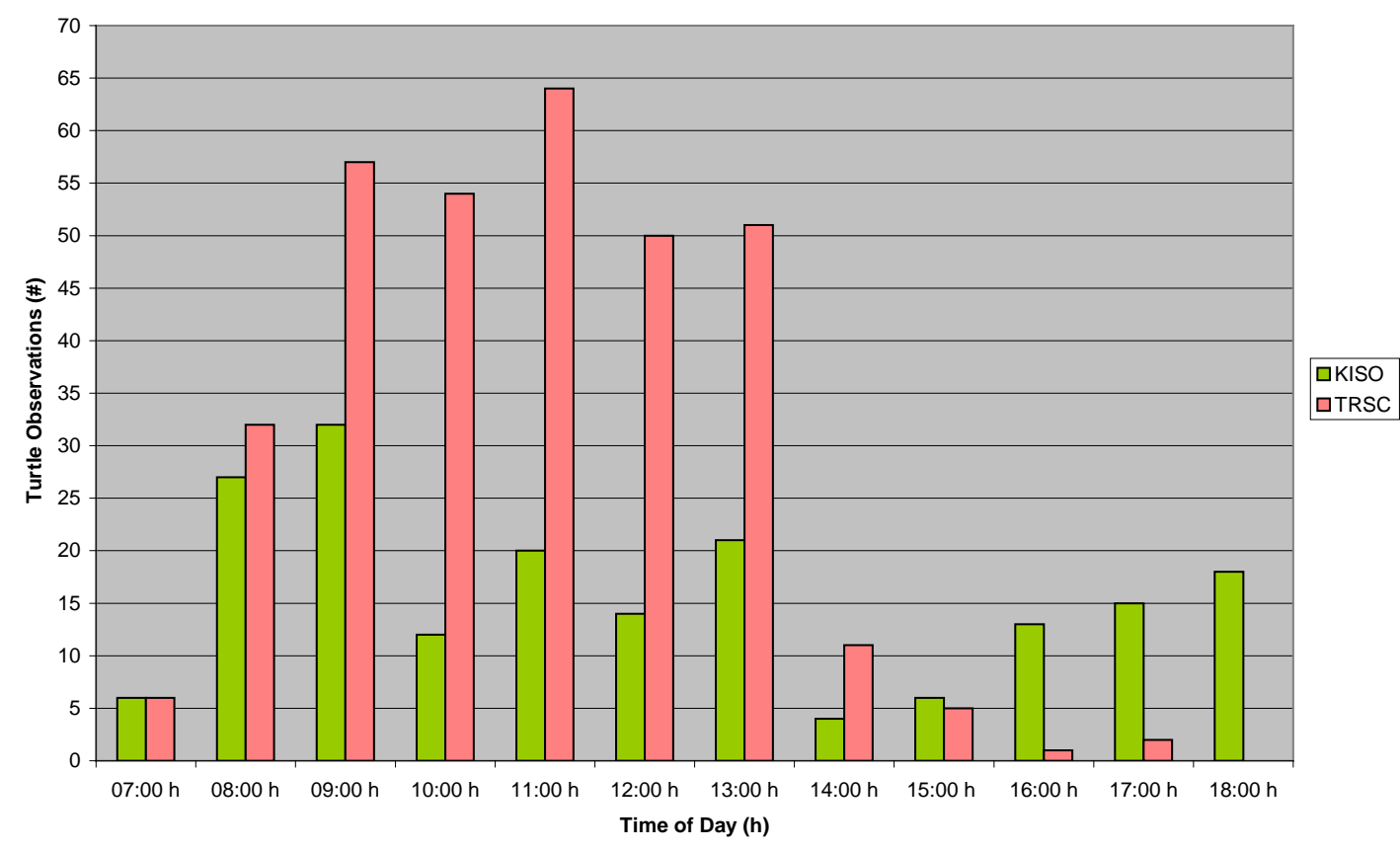

$B$

Basking Turtles-May 2007

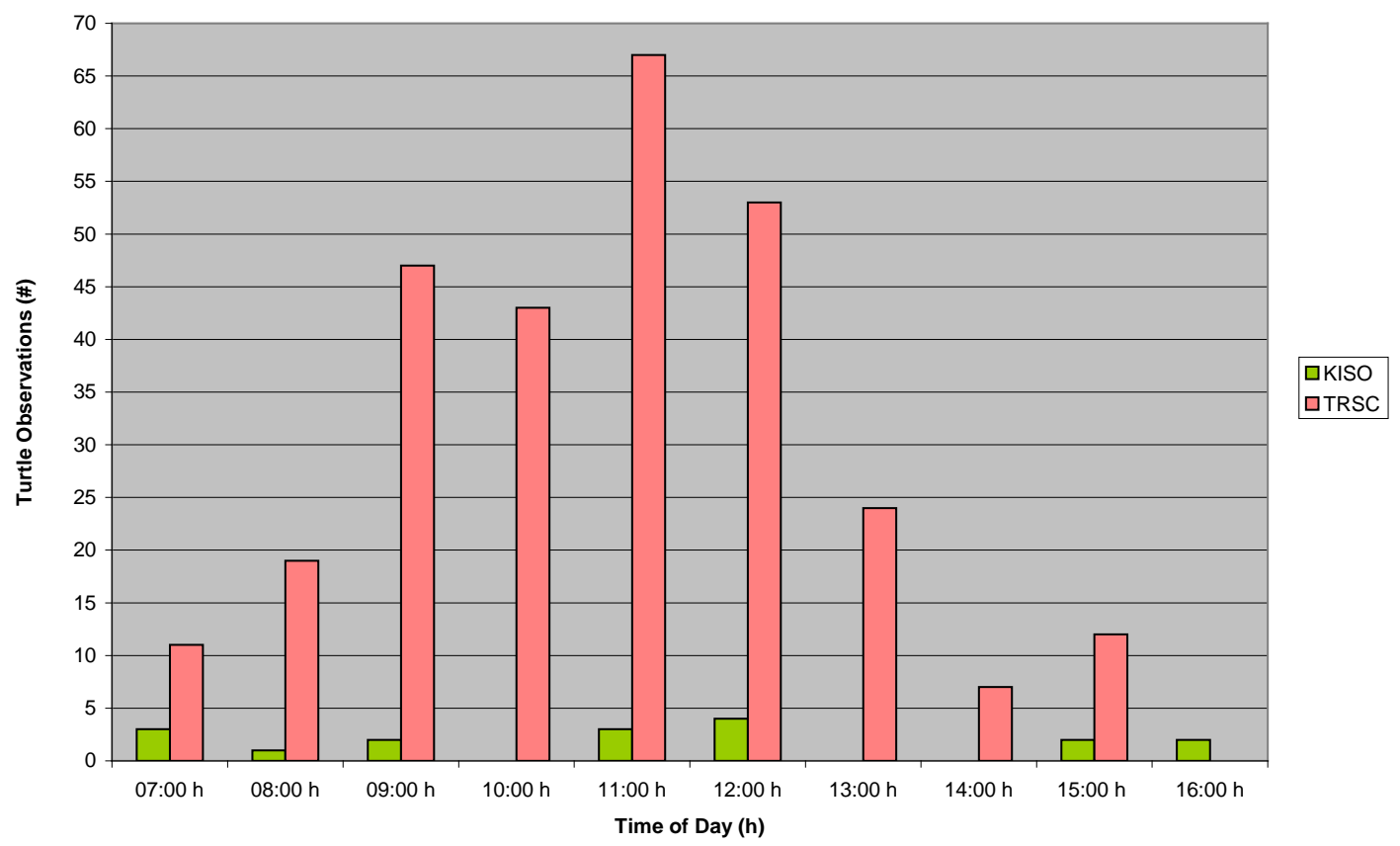

Figure 12. Daily activity pattern (number of turtles seen) of Sonora mud turtles (KISO, green bars) and red-eared sliders (TRSC, red bars) at Montezuma Well, Arizona, April through October 2007, based on systematic observations from the rim of the Well. A, April 2007; B, May 2007. 
C

Basking Turtles-June 2007

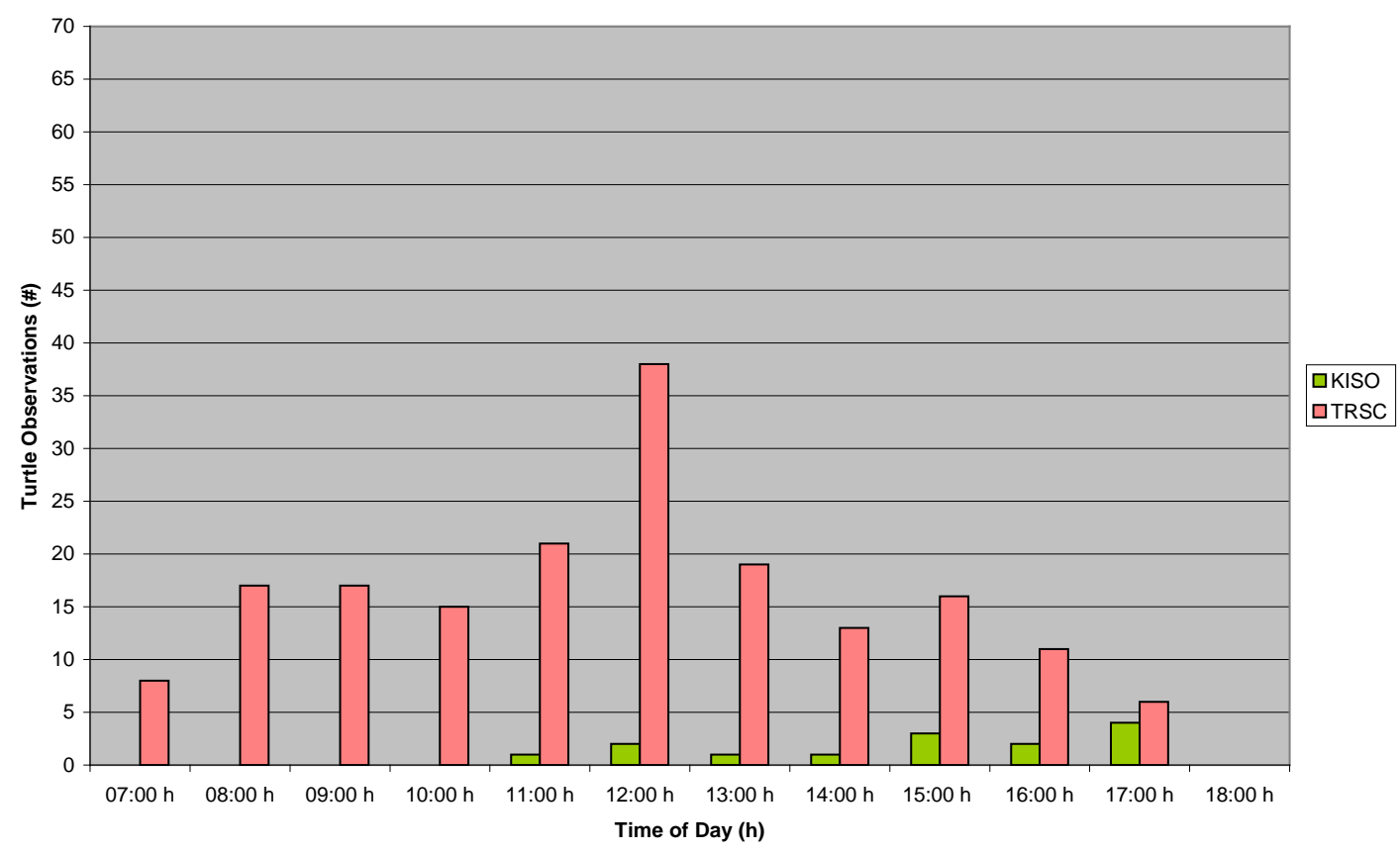

D

Basking Turtles-July 2007

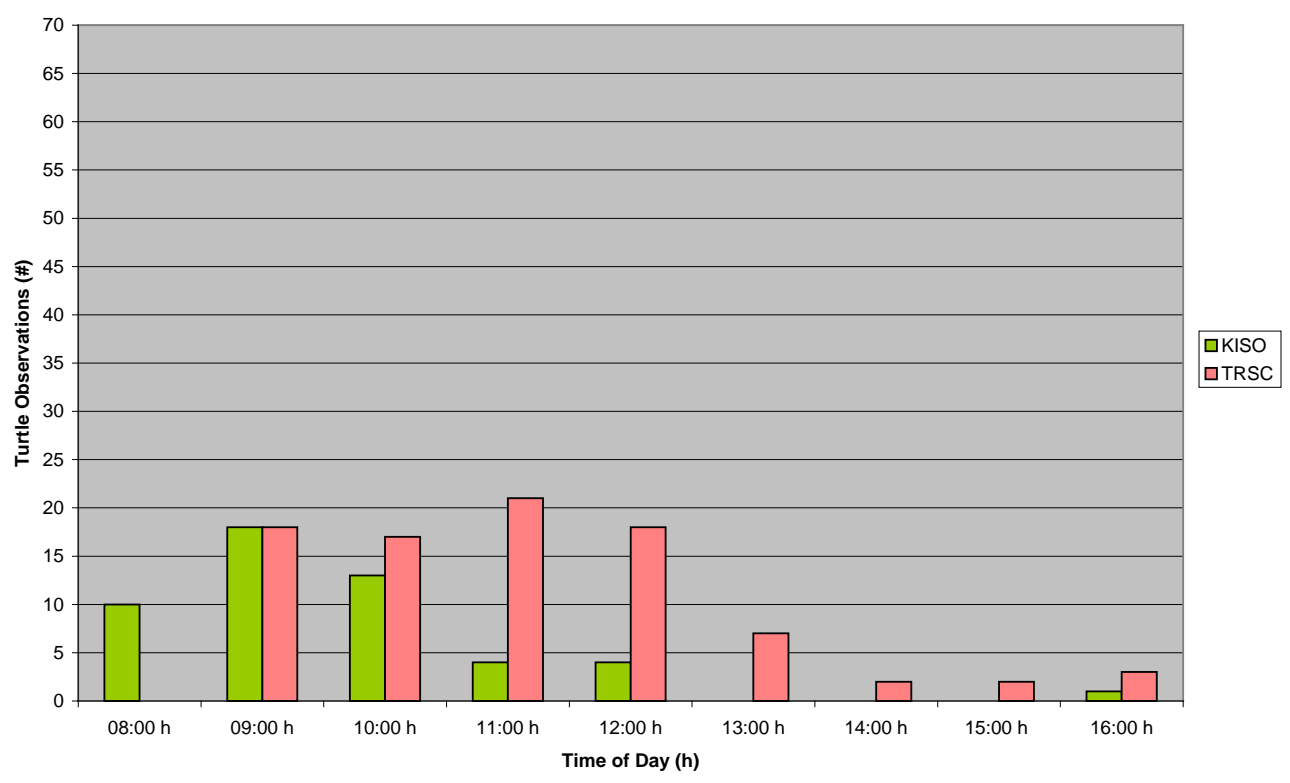

Figure 12. Daily activity pattern of mud turtles and sliders at Montezuma Well, Arizona-Continued.

C, June 2007; D, July 2007. 
Basking Turtles-August 2007

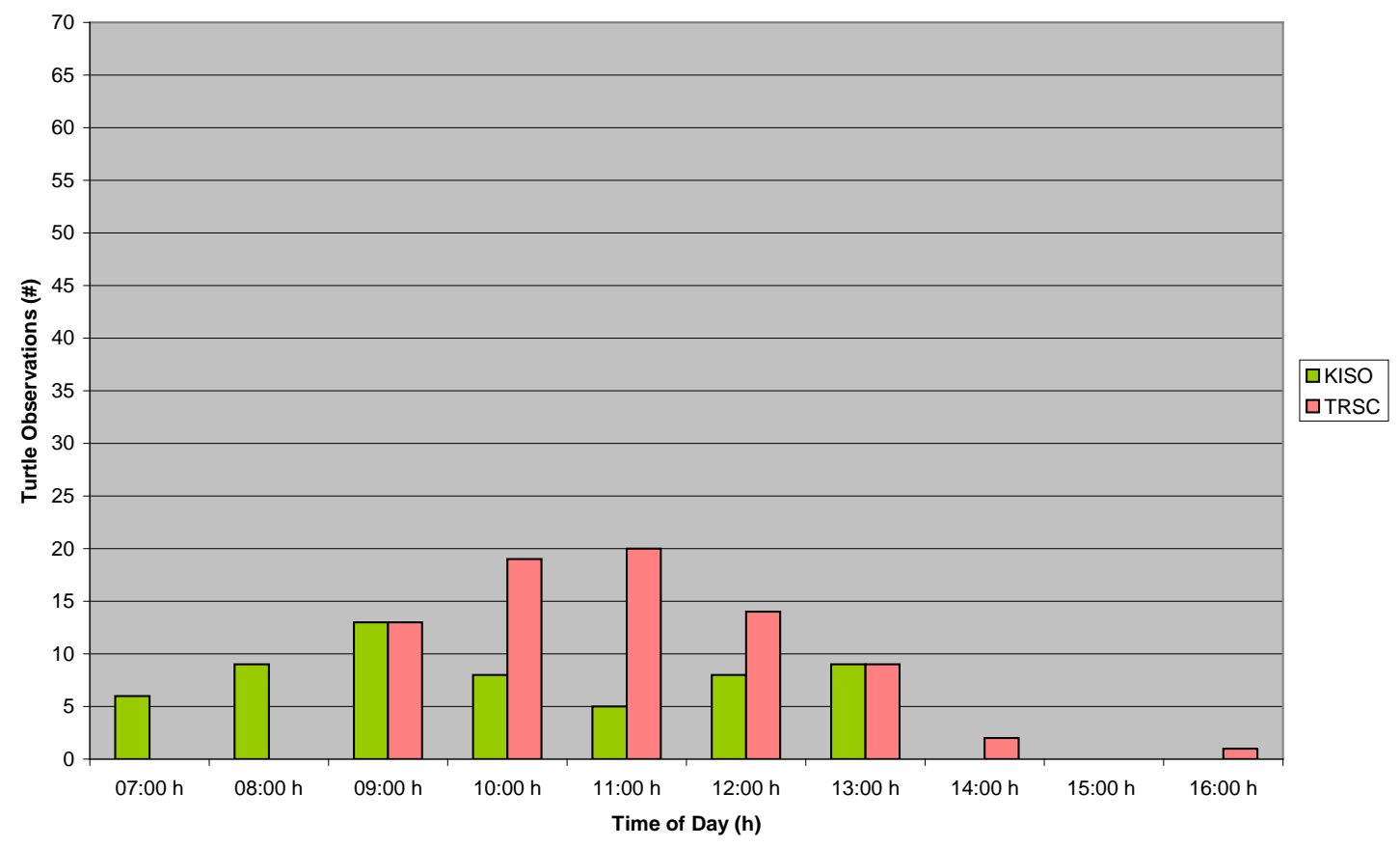

$F$

Basking Turtles-September 2007

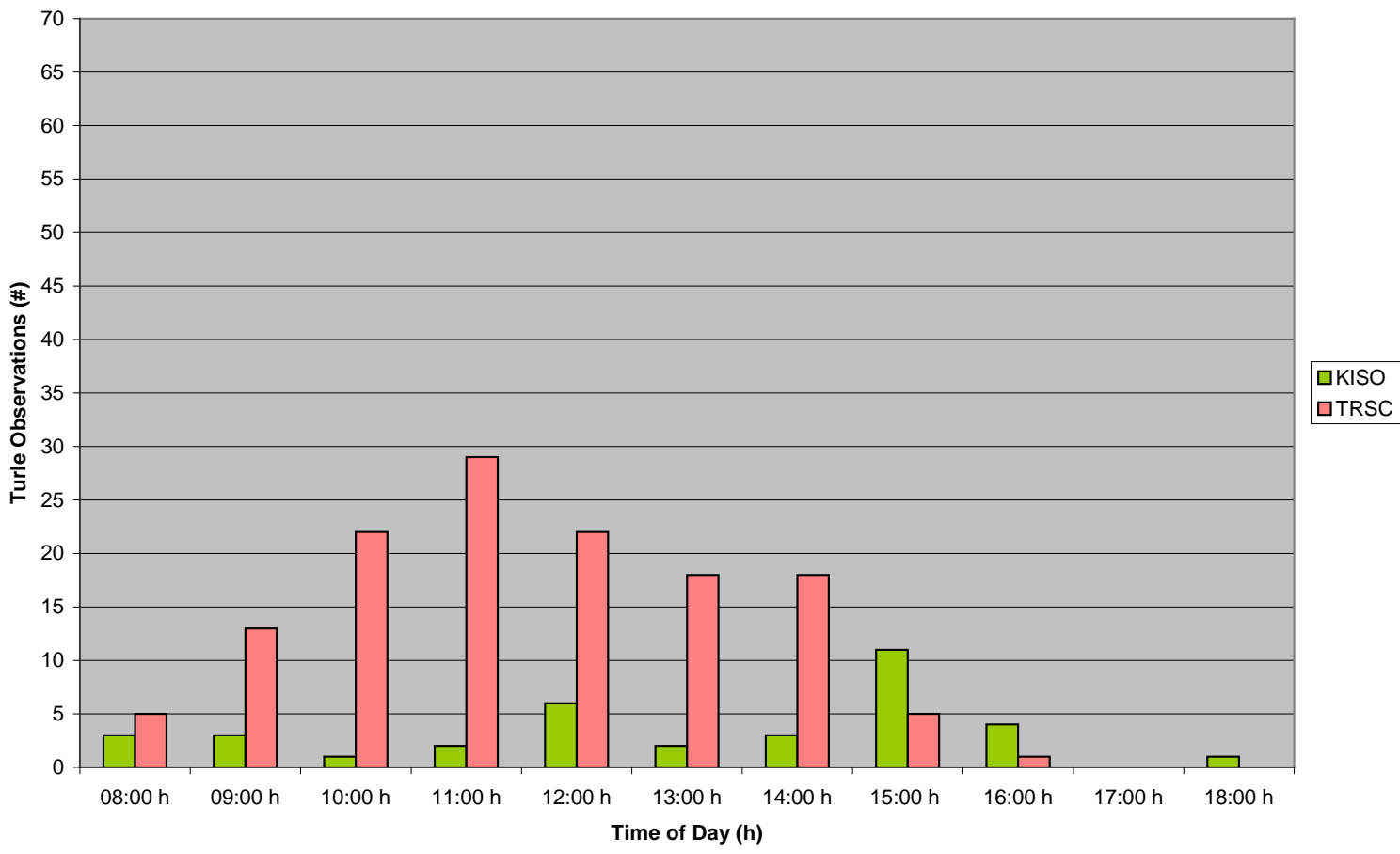

Figure 12. Daily activity pattern of mud turtles and sliders at Montezuma Well, Arizona-Continued.

E, August 2007; F, September 2007. 
Basking Turtles-October 2007

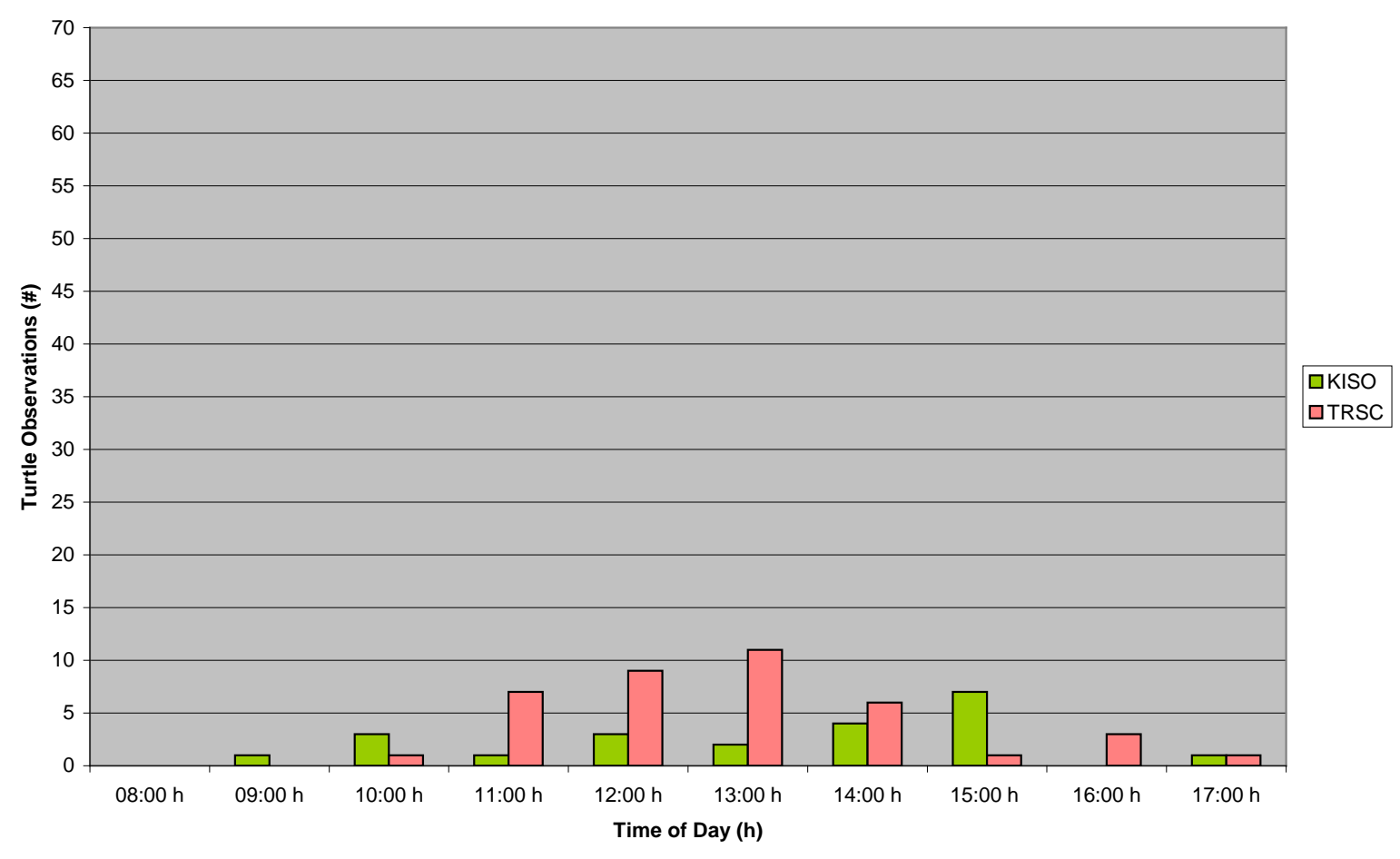

Figure 12 Daily activity pattern of mud turtles and sliders at Montezuma Well, Arizona-Continued. G, October 2007.

\section{Visitor Contacts/Outreach}

Interpretation and outreach are important priorities for NPS and the Western National Parks Association, who provided funding for this project. They specifically requested that we include an outreach and education component to this study. In addition, most of our fieldwork was in areas accessed by visitors, so there were numerous opportunities to interact with visitors to Montezuma Well. For these reasons, we always made time to talk about the turtle project with interested visitors. For both years of the study combined, we had nearly 1,000 visitor contacts, with 452 in 2007 and 535 in 2008. In addition to talking about the biology of the turtles and about aspects of the unique ecology of Montezuma Well, our contacts with visitors typically included discussions about issues with nonnative species, and why unwanted pets such as turtles should not be released into the wild.

We collaborated with staff of the Interpretation Division at Montezuma Castle National Monument in producing an interpretive flyer for the project. The project flyer is posted at the visitor contact station at Montezuma Well and at the U.S. Geological Survey (USGS) offices in Flagstaff, Arizona, and is also available as a handout from NPS. We also gave presentations on the turtle study at local conservation and nature events, including the Verde Valley Nature \& Birding Festival and "Science in the Park," an annual public education event in Flagstaff that highlights and encourages interest in science among grade-school children and adults. 


\section{Discussion}

\section{Field Effort}

During the $2 \mathrm{yr}$ of this study, we had over 500 trap-days of trapping effort using hoop nets and nearly 600 trap-days of effort with basking traps. Trapping effort with hoop nets averaged about 40 trap-days per month, ranging from 8 trap-days in March 2008 (a short, partial month) to 74 trap-days in July 2008. In addition to removing most of the nonnative turtles from the Well, this trapping effort provides a full $2 \mathrm{yr}$ of ecological data on the mud turtles at Montezuma Well. Taken together with previous studies of turtles in the Well (Rosen, 1987; Malone, 1999), this data is invaluable in understanding population trends, as well as adding to our knowledge of the biology and ecology of the poorly known Sonora mud turtle.

We tried several variations to increase capture rates with the hoop traps. We set out 91$\mathrm{cm}$ (3-ft) diameter hoop nets in addition to our standard 76-cm (2.5-ft) diameter hoop nets to see if this would increase captures of the larger sliders. However, we discontinued using the larger traps after a short trial, when we inadvertently captured one of the muskrats (Ondatra zibethicus) living in the Well. We also left hoop nets set for $48 \mathrm{~h}$ rather than $24 \mathrm{~h}$, to see if this might increase captures. However, trials with nets checked after $48 \mathrm{~h}$ did not increase capture totals. We also realized (from turtles that were left temporarily in traps) that some mud turtles were able to find their way out of traps. For this reason, we decided that 24-h checks were more efficient. On several occasions, we experimented with different kinds of bait, including several varieties of oily, canned cat food and other kinds of canned fish. We also tried cut-up fruit for attracting sliders. Ground or shredded cat food did not hold together and was more difficult to handle than whole sardines. In limited trials, none of the alternative baits worked better than canned sardines.

\section{Populations}

\section{Turtle Captures}

Considering all capture methods (hoop traps, basking traps, hand, and dip net), hoop traps accounted for the great majority of turtles captured, with 95 percent of the captures of mud turtles (225 of 237) and 71 percent of nonnative turtles (10 of 14). Basking traps accounted for a very small number of the mud turtles caught, but there was a conspicuous change in capture rates from 2007 to 2008 (table 3). In 2007, only one mud turtle was caught in the basking traps. A much smaller total number of mud turtles was caught in 2008, but six of these were caught in the basking traps. This difference in numbers of turtles captured with the two methods was significant ( $p=0.0018$, Fisher's Exact Test).

Although the hoop traps also caught more nonnative turtles than did the basking traps, the basking traps were still valuable. They accounted for 3 of 14 of captures of nonnative turtles (21 percent), and it is possible that they captured some individuals that were avoiding, or simply were not attracted to, the numerous hoop traps set in the vicinity of the basking traps. An added advantage of the basking traps is that they are much less time intensive than the hoop nets. We set them out at the beginning of the season, and they operated continuously until we retrieved them in the fall. The only time required for them was a quick check whenever we were at the Well. The hoop nets, in contrast, required two separate trips to the Well and several hours time to set them one day, then check them the next. 
In addition to the nonnative red-eared sliders, we also captured single individuals of Pacific pond turtle (in September 2007) and yellow-bellied slider (in June 2008). The Pacific pond turtle is native to the Pacific coastal region of North America, from northern Baja California to Washington State. It had not previously been documented from Arizona, or even near Arizona, and the individual that we captured presumably represents a released captive. The yellow-bellied slider is native to the Gulf Coast States and southern Atlantic States, from Alabama to Virginia. Along with the red-eared slider, the yellow-bellied slider was formerly common in the pet trade. The presence of these two additional nonnative taxa at Montezuma Well seems to clearly point to repeated releases of nonnative turtles in Montezuma Well. With no others of their kind in the Well, the pond turtle and yellow-bellied slider clearly were not born there. These turtles also appeared to be of different ages and their size and age indicates they were probably released later than the first red-eared sliders at the Well. All of this suggests that introductions of nonnative turtles at the Well occurred over an extended period of time.

\section{Marking and Recaptures}

We noted that some recaptured turtles had marks that were rounded and looked old. Such a shallow, rounded notch apparently reflects the amount of growth since the turtle was marked, rather than simply how old the mark is. On most of our recaptures from Malone's study (1999), the marginal notches were conspicuous, deep, and sharp-edged. One turtle (code $\mathrm{CJN})$, however, grew substantially between captures. Malone marked his turtle as $\mathrm{J}$ and measured its carapace length as $76 \mathrm{~mm}$. We subsequently recaptured a turtle marked as $\mathrm{J}$ that measured $141 \mathrm{~mm}$ carapace length and added notches for C and N. Our comments for this turtle specifically note "Notch in J old and rounded." This turtle had grown approximately $65 \mathrm{~mm}$ between captures. Similarly, Matthew Malone (written commun., March 9, 2009) noted that the marks on his recaptures of turtles marked by Rosen were "were very hard to recognize." These included turtle 2IN, which grew from $72 \mathrm{~mm}$ (when Rosen marked it as $\mathrm{N}$ in June 1983) to $130 \mathrm{~mm}$ when Malone caught it in November 1999, and turtle LN, which grew from $84 \mathrm{~mm}$ when Rosen caught and marked it in August 1983 to $129 \mathrm{~mm}$ when Malone caught it in October 1999.

The two turtles that we identified as recaptures from Rosen's study are AINP (originally marked as P) and AOV (originally marked as O). When we first captured AINP in May 2007, we did not even notice a notch in $\mathrm{P}$, and we added notches for A, I, and N. When we recaptured this individual on June 6, 2007, we saw that there was a shallow, rounded, but still clearly recognizable notch in P (whereupon the turtle's code became AINP). Both Rosen and Malone marked individuals as "P." However, Malone's turtle P had a carapace length of $122 \mathrm{~mm}$. We first measured AIN/AINP at $124 \mathrm{~mm}$, which would represent minimal growth. Rosen's P, on the other hand, was only $78 \mathrm{~mm}$ when he marked it in June 1983. Given the distinctness of Malone's marks on other turtles (when we recaptured them after relatively little growth), we are confident that this turtle was the individual that Rosen marked as $\mathrm{P}$, after growth of some $46 \mathrm{~mm}$.

For turtle AOV, we also specifically noted "shallow notch on O" in our comments (we added notches for $\mathrm{A}$ and $\mathrm{V}$ ). This turtle measured 131 and $132 \mathrm{~mm}$ when we captured it on two separate occasions. Malone's $O$ was $114 \mathrm{~mm}$ (so growth would have been about $17 \mathrm{~mm}$ ), while Rosen's O was $72 \mathrm{~mm}$ (growth of $59 \mathrm{~mm}$ ). It is possible that this is the turtle that Malone marked, but, considering that we have not seen notch marks reduced to this shallow, rounded condition in any other turtles with less than $45 \mathrm{~mm}$ growth, we consider it much more likely that $\mathrm{AOV}$ is the turtle that Rosen originally marked. 


\section{Sex Ratio and Size Structure}

Our capture data are significantly biased toward males, compared to a hypothetical 50:50 ratio. Biased adult sex ratios are well known in turtle populations. Lovich and Gibbons (1990) documented five factors that contributed to adult sex ratio variation in turtles: (1) sampling bias; (2) differential emigration and immigration; (3) differential mortality; (4) environmental sex determination; and (5) bimaturism, or differences in the timing of maturity between the sexes. The earlier maturing sex typically matures at a smaller body size relative to the later maturing sex. Holding all other factors constant, this means that the sex that matures first predominates numerically. Given that adult female body size is larger than that of adult males in many turtles (including mud turtles in the Well), males are predicted to mature earlier and predominate numerically. Hence, the biased male sex ratio at the Well is not unexpected.

Additional work is needed to assess whether males do outnumber females in the Montezuma Well population, or whether the observed male:female ratio is because of a higher capture probability for males, or some other factor. Other studies of Sonora mud turtles (Hall and Steidl, 2007) have found that males have larger home ranges and longer average movements than females. The average home range length of males was five times that of females, and individual movements of males averaged two and a half times the distance of average female movements. The study by Hall and Steidl was conducted in stream habitats, so it is not directly comparable to the pool habitat of the Well. However, if males at the Well also have significantly larger home ranges and movement distances, they may simply be more likely to encounter our hoop traps. This could also account for the higher number of males captured and the observed imbalance in the sex ratio.

The size structure of both the native mud turtles and the nonnative sliders also appears to be strongly biased toward larger individuals. The smallest slider, in fact, was the lone individual captured in Beaver Creek (an individual of unknown sex, carapace length $127.8 \mathrm{~mm}$ ). All of the sliders captured in Montezuma Well were greater than $175 \mathrm{~mm}$ carapace length. Likewise, about 80 percent of the mud turtles captured in 2007 and 2008 were larger than $120 \mathrm{~mm}$ carapace length (the size we defined as adult for the Well turtles) and 90 percent were larger than $110 \mathrm{~mm}$. Interpretation of these size data can be confounded by the fact that young turtles, generally, are more secretive and difficult to catch (Congdon and others, 1993; Ernst and Lovich, 2009 - see, for example, account for Sternotherus depressus). However, our preliminary analyses of the data of Rosen (1987) and Malone (1999) suggest that they caught larger proportions of small/young turtles than we did. Hence, our size data for mud turtles may indicate a real shift toward larger, older individuals. For the nonnative sliders, their conspicuous basking behavior provides an additional source of information on size structure of the population. The great majority of turtles that we observed in our basking observations were sliders, despite their lower numbers in the Well. During our long hours of basking observations, we recorded mostly large sliders, with relatively few medium-size and no small individuals. This seems to indicate that there is little successful reproduction of the sliders within Montezuma Well.

We will analyze sex ratios, size/age structure, and longevity in more detail in future work. Of particular conservation and management interest in this regard is the extent to which the age structure of the mud turtle population appears to have shifted toward older individuals since the time of Rosen's (1987) and Malone's (1999) studies. This finding could reflect poor reproduction or poor survival of young turtles, and may be important in understanding the current decline of Sonora mud turtle numbers at the Well (see below). 


\section{Turtle Numbers}

There are many challenges in accurately estimating the population size of animals in the wild. Even in the best circumstances, animals can be difficult to observe or may become trap shy, their behavior may change from one trapping session to the next, and individuals may enter and leave the study area. In trapping studies, low capture probabilities pose problems with accurate calculations. For the turtle trapping at the Well, capture probabilities were all well under 0.1 . The estimators that we compared (Schnabel, Schumacher, and the null model) are all simple estimators, and these analyses need additional work. Nonetheless, all of the information that we have-from capture rates (fig. 10), from mark-recapture population estimates (table 8), and from visual observations - clearly indicates a major decline in numbers of Sonora mud turtles in the Well from Rosen's study, to Malone's study, to our own surveys. Together with the capture and removal of nonnative turtles from the Well, documenting this decline in the mud turtle population is the most significant result of our work and clearly indicates the need for additional monitoring and research on this population.

Because our primary objective was to remove nonnative turtles from the Well, we did not attempt mark-recapture estimation of their numbers. However, our intensive observations of the turtles in Montezuma Well (the basking and activity observations) showed that with the removal of the additional sliders captured in 2008 , there may now be as few as three sliders left in the Well. In our basking observations in late July through early September 2008, and during incidental observations thereafter, we have only seen a total of three sliders. These individuals are distinctively marked and are recognizable at a distance. They include an adult male, with a conspicuous, subterminal dark band along the posterior carapace, an adult female, with visible red ear-stripes and yellow radial lines on either side of the carapace, and a half-grown juvenile, with vibrant red "ears," lighter olive-gray carapace, and yellow highlights on the marginal scutes. If our observations are an accurate reflection of the number of sliders remaining, the total number of nonnative turtles in the Well in 2007 and 2008 was probably less than 20 individuals.

\section{Injuries and Mortality}

There are few descriptions of injuries in Sonora mud turtles (for example, Hulse, 1976). However, we found that mud turtles at Montezuma Well suffered a wide range of injuries, ranging from minor scrapes and broken claws to major damage to the shell. Not surprisingly, the number of injuries increased with size (and hence approximate age) of the turtles (table 9). One of the most significant injuries that we recorded was damage to one or both eyes, resulting in blindness in the affected eye(s). These eye injuries affected about 8 percent of the turtles captured, but we do not know their cause. Despite the blindness, there was no indication that these turtles were in poor condition otherwise (for example, low weight relative to carapace length). There were two females among the turtles that had injured eyes, and both of them were captured twice. Female ALW was caught on May 15, 2007, with no eggs, and on September 6, 2007, with 7 eggs. Female CKV was the individual that was blind in both eyes. She was x-rayed on June 18, 2008, and did not have eggs.

We found a total of five dead turtles (not counting old shell remains that could not be aged). One was found in 2007, and four were found in 2008. The dead turtles included two males (carapace lengths 118.5 and $113 \mathrm{~mm}$ ), one female $(126.5 \mathrm{~mm})$, and two juveniles (86 and 82 $\mathrm{mm})$. In most cases, we could not identify cause of death. However, even the adult-sized individuals were smaller than average for the population, so none of the deaths were thought to be from old age. One mortality (the $126.5 \mathrm{~mm}$ female, code BKN) may have been the result of 
predation. We found the dead turtle's cleaned-out but relatively fresh shell floating near shore, with a linear series of punctures in the carapace. The spacing of the punctures corresponded to the tooth spacing of a medium-sized carnivore, such as a fox. One of the punctures penetrated to the inside of the shell, where there was associated coagulated blood, suggesting the turtle was alive when the shell punctures occurred.

We saw numerous excavated nests but have not quantified the level of predation on eggs. However, predation of turtle nests within Montezuma Well may be high. The cliffs that surround the Well provide den sites and retreats for a variety of small and medium-sized carnivores that may feed on turtle eggs. During this study, we have seen or otherwise recorded gray fox (Urocyon cinereoargenteus), hog-nosed skunk (Conepatus leuconotus; trap capture in the Well), and spotted skunk (Spilogale gracilis; infrared camera photo of individual in the Well,) within the walls of the Well. Raccoons (Procyon lotor), ringtails (Bassariscus astutus), and striped skunks (Mephitis mephitis) also occur in the Montezuma Well area and are potential nest predators (Schmidt and others, 2006).

\section{Reproduction}

The rate of reproduction in female mud turtles (as measured by adult individuals radiographed between late April and late September) was relatively low in 2007 and 2008. From late April to late September 2007 (our early and late dates for females with eggs), 57 percent of adult females from Montezuma Well that were radiographed were gravid, and 64 percent of Beaver Creek females were gravid. From smaller sample sizes in 2008, 50 percent of Well females and 25 percent of Creek females had eggs (table 10). In his fieldwork in 1983, Rosen (1987) found a substantially higher proportion of females gravid, both in early summer, late summer, and overall (table 13). Rosen also collected data on sites in southern Arizona. In comparing his data for one site (Tule Creek) to information collected previously by Hulse (1982), Rosen noted that the proportion of females that were gravid varied widely between years. This year-to-year variation could account for differences between our 2007 and 2008 observations and those of Rosen in 1983. We do not know of possible reasons for such variation in the stable environment of the Well, however.

Table 13. Comparison of female reproductive rate in first and second halves of season, between Rosen's (1987) data in 1983 and observations in 2007 and 2008, at Montezuma Well, Arizona.

\begin{tabular}{lrrrrrr}
\hline \multicolumn{1}{c}{ Study, year } & \multicolumn{2}{c}{ April 23-July 15 } & \multicolumn{2}{c}{ July 16-Sept 28 } & \multicolumn{2}{c}{ Total season } \\
& number & \% gravid & number & \% gravid & number & \% gravid \\
\hline Rosen, 1983 & 17 & 88.2 & 31 & 74.2 & 48 & 79.2 \\
This study, 2007 & 12 & 41.7 & 18 & 66.7 & 30 & 56.7 \\
This study, 2008 & 8 & 50.0 & 7 & 57.1 & 15 & 53.3 \\
\hline
\end{tabular}

\section{Behavioral Observations}

The basking observations provide important ecological information on the sliders and mud turtles in Montezuma Well, as well as ancillary information on activity and behavior of both species. These observations may also yield important insights into the interactions between the native mud turtle and the nonnative slider. Analysis of the basking and behavioral observations to date shows clear patterns in both daily and seasonal activity patterns (fig. 12). Preliminary 
analysis of spatial patterns of turtle basking, aquatic basking, and other activity in the waters of the Well also shows evident trends, possibly in relation to sun angle, bottom depth, aquatic vegetation, and other aspects of habitat. Water temperature in the Well is much more constant, both seasonally and diurnally, than in most aquatic habitats. Nonetheless, Blinn (2008) noted variations that are probably important to both the mud turtles and the sliders. Water temperature at the surface of the Well may be as high as $26-27^{\circ} \mathrm{C}$ in mid-summer (measured by us, summer 2009). This is $5^{\circ} \mathrm{C}$ or $6^{\circ} \mathrm{C}$ warmer than the water temperature at depth in the summer, and is similarly warmer than winter water temperatures, which are $19-20^{\circ} \mathrm{C}$ throughout the water column. In addition, summer water temperature near the surface in areas of dense aquatic vegetation may be over $30^{\circ} \mathrm{C}$ in the summer because of absorption of infrared radiation by the plants (Blinn, 2008). Brattstrom (1965) reported that Kinosternid turtles (the group that includes the Sonora mud turtle) have a mean activity temperature in the low $20^{\circ} \mathrm{C}$ range (range for 19 individuals, $16.2-28.8^{\circ} \mathrm{C}$ ), while Emydid turtles (the group that includes the slider) have activity temperatures that average over $25^{\circ} \mathrm{C}$ and extend above $35^{\circ} \mathrm{C}$. These differences in water temperature probably affect both the mud turtles and the sliders but may be more important to the sliders.

\section{Management Implications}

Nonnative slider turtles had been introduced into Montezuma Well by the late 1960s or early 1970s. We reviewed natural history observation notes maintained by NPS staff at Montezuma Castle National Monument, and the earliest definite record that we found of redeared sliders in the Well was from May 1971, when two were recorded by NPS staff. The observation record specifically noted "red stripe behind the eye." During his 1983 fieldwork, Rosen recalls seeing only a few sliders (Phil Rosen, written commun., 2008), and neither he nor Matthew Malone (in 1999) captured any sliders in the Well. However, in April 1993, Erika Nowak of the USGS Colorado Plateau Research Station at Northern Arizona University found and photographed a medium-sized slider in the irrigation canal that links the outflow of Montezuma Well with Beaver Creek (photo examined by the authors).

The introduction and gradual increase in numbers of nonnative turtles has coincided with a substantial decline in the population of the native Sonora mud turtle in the Well. We do not have direct evidence on potential mechanisms for negative effects of the introduced sliders on mud turtles in the Well. However, some negative influence of sliders - such as competition for basking sites or other resources - appears to be the most likely explanation for the decline of the mud turtles. We do not know of any other source of increased mortality, direct disturbance to the turtles, habitat degradation, or other recent changes in the habitat of the Well. As part of a national monument, with regular ranger patrols, oversight of visitors and gates that are locked at night, the Well is protected against most negative effects that may be found in unprotected habitats. A substantial body of ecological study (for example, Boucher and others, 1984; Blinn 2008) has shown that the phytoplankton community that forms the base of the Montezuma Well food web has a high degree of consistency both in species composition and measures of abundance. This outcome is the result of the remarkably uniform thermal and chemical conditions of the aquatic environment of the Well and presumably translates into a generally stable food supply for the turtles. All access to the waters of the Well is restricted, so effects of the many visitors to the Well (for example, through collecting, or by release of additional nonnative species) should be minimal. 
In addition to the introduced sliders, there are still some other outside influences that may affect mud turtles in the Well. People do occasionally trespass on the monument during hours when it is closed. On at least three occasions, we found that someone had disturbed and vandalized the boat that we used in this study_presumably some person or persons going down into the Well after the monument was closed for the day. Hence, there is still the possibility that more nonnative turtles could be released into the Well. Another potential threat to the mud turtles is increased predation on nests and eggs by small carnivores. There is a diverse community of small carnivores in and around the Well, and some of these species dig up and feed on turtle eggs. Though we do not have data on population trends or effects of these species, it is possible that small carnivore populations may have increased with encroaching urbanization near the Well. Other studies have documented such increases in small carnivore populations because of urban and suburban influences (for example, Crooks and Soulé, 1999), and these changes, in turn, may be associated with increased predation on turtle nests and eggs (Temple, 1987; Congdon and others, 1993).

We will continue analyzing the wealth of data obtained during the 2-yr study of the turtles of Montezuma Well. In the meantime, our results to date point to the following considerations for management:

\section{Removal of last sliders}

Additional efforts to capture and remove the few remaining nonnative turtles will return the unique Montezuma Well ecosystem to a more natural state. It will also assure that the sliders do not begin to build their numbers back up through reproduction, which would negate the progress made through the removal efforts to date. On the basis of both our capture data and basking observations, slider activity is highest during the spring. Half of all sliders captured in 2007 and 2008 were caught in the month of May, and activity in the latter part of the summer has been very low. Hence, capture of the last remaining sliders should be targeted for the spring, when turtle activity increases again. Basking traps require little time and are relatively effective at targeting the sliders. The sliders spend much of their time in the area of dense aquatic vegetation in the shallows on the south and southwest margins of the Well. One or more basking traps, combined with hoop net trapping concentrated in the area of aquatic vegetation, would provide the best opportunity to trap the remaining sliders.

\section{Population monitoring}

A relatively simple population monitoring effort would help assure that all sliders have been removed and would also provide early warning in the event that additional nonnative turtles were released in the Well. Counts of mud turtles would also provide additional data on the population trend of this species and may also reveal changes in behavior and habitat use by the mud turtles in the absence of sliders. Appendix 2 outlines a population monitoring program that could be carried out by NPS staff or volunteers with a minimum of training.

\section{Continued public outreach and education}

Throughout our work in 2007 and 2008, visitors to Montezuma Well were always interested in hearing and learning about the turtles, and a population monitoring effort could easily be combined with continued interpretation and education. One of the purposes of this type of outreach would be to reduce or prevent future releases of nonnative turtles into the Well. Montezuma Well interpretive staff have already developed an engaging and informative poster about the turtles of the Well and the potential threat from nonnative turtles. Staff engaged in the monitoring program would have a very good opportunity to talk to the visiting public, both about 
the unique biological community of the Well and about the problems associated with nonnative species.

\section{Follow-up research}

Our analyses show a substantial decline in the mud turtle population in Montezuma Well and clearly point to the need for additional research on the causes of the decline. Further analysis of the data collected in 2007 and 2008 should yield additional insights into the decline. However, additional study is merited on the size/age structure of the mud turtle population, the level of recruitment and mortality, and potential threats to the population. Besides effects of the nonnative sliders, the primary concern that we can identify is possible increased predation on turtle nests by small carnivores, which may be associated with increased development surrounding Montezuma Well. Neither changes in small carnivore numbers nor changes in predation on turtle nests have received any study to date.

Research on the cause of decline may tie in directly to removal of the sliders. The foremost goal of the turtle project at Montezuma Well was to remove the nonnative sliders from the Well. In the process, however, the work provided an experimental system for assessing the possible effects of nonnative sliders on mud turtles. It also allows an opportunity for evaluating changes in the mud turtle population after the removal of the sliders. Given that environmental conditions at the Well are exceptionally stable (Blinn, 2008), the only significant source of variation for the Sonora mud turtle population before and after intensive trapping should be the removal of the slider turtles. Turtles are capable of responding rapidly to enhanced resource availability (Lovich and others, 1999), so a response by the mud turtle population to slider turtle removal may be evident relatively quickly.

\section{Products of the Montezuma Well Turtle Project}

This relatively small project has yielded a substantial return in terms of presentations, public education, and published and unpublished reports. The work has had other benefits, not least of which has been working with NPS staff at Montezuma Well in the trapping and data collection process. This has added substantially to what we have learned about the turtles and their biology and ecology. For NPS staff, it has provided increased understanding, hands-on experience with the research process, and opportunities for interpretation to visitors to the Monument. The various products of the Montezuma Well turtle project-including planned publications - are described below.

\section{Reports and Presentations}

Particularly for a small project, this study has been quite productive for the number of scientific presentations and publications produced. The original motivation for this study was to evaluate potential threats of introduced red-eared sliders in the Well ecosystem generally and to the native Sonora mud turtles specifically. Sliders have been introduced into aquatic habitats in many other areas of the world, so our results from the Well are potentially valuable to management in other areas dealing with nonnative turtles. While a few sliders still remain in Montezuma Well, their removal remains an important goal for the National Park Service. If sliders are eventually completely removed from the Well ecosystem, we will seek opportunities to investigate and report on the population response of the mud turtles.

Sonora mud turtles are one of the least studied turtles in North America north of Mexico. The data gathered over the past $2 \mathrm{yr}$ on this poorly known species will be particularly valuable 
when combined with previous studies of mud turtles in the Well, yielding insights on long-term trends and details of biology and ecology that could not be gained from a short-term study. We are working with the authors of these previous studies (Rosen, 1987; Malone, 1999) to synthesize and analyze the entire set of data on the turtles in the Montezuma Well system, which now span over 25 years.

Scientific products from the Montezuma Well project to date include seven presentations at scientific conferences and two scientific manuscripts. One of the scientific presentations on the Montezuma Well turtle studies was presented to an international audience at the Sixth World Congress of Herpetology, in Manaus, Brazil, in August 2008. The first of several planned scientific manuscripts highlights unusual mud turtle food items observed at the Well. The second publication (in preparation) describes and analyzes aspects of the reproductive biology of Sonora mud turtles at Montezuma Well. Presentations and reports from this work (both completed and planned) include the following.

Presentations:

- Aspects of the Ecology of Sonora Mud Turtles at Montezuma Well (Ninth Biennial Conference of Research on the Colorado Plateau, Flagstaff, Arizona, October 2007; J. Lovich, presenter)

- Turtles in the Well: aspects of the ecology of Sonora mud turtles at Montezuma Well, Arizona, USA (Sixth World Congress of Herpetology, Manaus, Brazil, August 2008; J. Lovich, presenter)

- Turtles in the Well: Aspects of the ecology of Sonora Mud Turtles at Montezuma Well, Arizona, USA (Turtle Survival Alliance symposium, Tucson, Arizona, Fall 2008; J. Lovich, presenter)

- Reproductive ecology of female Sonora mud turtles (Kinosternon sonoriense) in Montezuma Well, Arizona: optimal egg size in a suboptimal environment? $\left(23^{\text {rd }}\right.$ Annual Desert Symposium at the Desert Studies Center in Zzyzx, California, April 2009; S. Madrak, presenter; paper received Best Student Paper award)

- Reproductive ecology of Sonora mud turtles (Kinosternon sonoriense) at Montezuma Well, Arizona: optimal egg size in a suboptimal but stable environment (Turtle Survival Alliance symposium, Fall 2009; J. Lovich, presenter)

- Reproductive ecology of female Sonora mud turtles (Kinosternon sonoriense) at Montezuma Well, Arizona: optimal egg size in a suboptimal environment? (Biennial Conference of Research on the Colorado Plateau, Flagstaff, Arizona, October 2009; J. Lovich, presenter)

- Population decline of Sonora mud turtle (Kinosternon sonoriense) at Montezuma Well, Arizona (Tenth Biennial Conference of Research on the Colorado Plateau, Flagstaff, Arizona, October 2009; C. Drost, presenter)

Publications:

- Lovich, J., Drost, C., Monatesti, A.J., Casper, D., Wood, D.A., and Girard, M., 2010, Reptilian prey of the Sonora mud turtle (Kinosternon sonoriense) with comments on saurophagy and ophiophagy in North American turtles: Southwestern Naturalist, v. 55, p. 135-138

- $\quad$ Lovich, J.E., Madrak, S.V., Drost, C., Monatesti, A.J., Casper, D., and Znari, M., Reproductive ecology of female Sonora mud turtles (Kinosternon sonoriense) at Montezuma 
Well, Arizona: optimal egg size in a suboptimal environment? (pending submission, Journal of Zoology)

Future work:

- Demography and population decline of Sonora mud turtle population in Montezuma Well [Population biology and population trends, including population estimation calculations, size/age structure, and comparisons to past studies]

- Growth and longevity of Sonora mud turtle in Montezuma Well

- Activity patterns and behavior in Montezuma Well and adjacent Beaver Creek [Basking data and other observational data; effects of the unique, thermally stable environment of Montezuma Well, combined with the area being near the northern end of the species range]

- Sonora mud turtle reproductive biology at Montezuma Well and adjacent Beaver Creek (particularly clutch size and egg size) compared to other mud turtle populations in Arizona

- Nonnative turtles in Montezuma Well, including possible interactions with and effects on mud turtle, and removal of sliders from the Well.

- Aspects of Sonora mud turtle ecology in the unique environment of Montezuma Well [Including comparisons to Beaver Creek]

- Food habits of Sonora mud turtles in Montezuma Well

\section{Public Education and Collaborations}

During our fieldwork for this project, visitors were very interested in hearing about the native and nonnative turtles, and our research activities at Montezuma Well. We worked with NPS staff throughout the project period, particularly on interpretive and educational aspects of the study. Presentations and public education materials from this project included:

- "Turtles in Trouble" - an informational site bulletin and poster prepared in cooperation with interpretive staff at Montezuma Castle National Monument, describing the Sonora mud turtle at Montezuma Well, its unique habitat, and possible threats from red-eared sliders

- "Turtles in the Well: aspects of the Ecology of Sonora Mud Turtles at Montezuma Well, Arizona, USA," Verde Valley Nature \& Birding Festival (April 2008)

- Video presentation filmed for the nature program "Animal Planet" (filmed in April 2008, not yet aired in United States)

From June through August 2008, Dr. Mohammed Znari, a vertebrate biologist and turtle researcher from Morocco, assisted us on this project. Dr. Znari was in the United States on a Fulbright Scholar grant, sponsored by Jeff Lovich and the USGS Southwest Biological Science Center. Dr. Znari's interests and expertise include physiological studies, and he worked with us on ideas for studying the physiological response of the turtles to the extremely high carbonate levels in the water of the Well. We developed a joint proposal to measure basic blood chemistry parameters, compare blood chemistry and breathing rates of the mud turtles in the Well and those in adjacent Beaver Creek, and conduct translocation experiments to evaluate short-term changes in response to the two very different environments. The proposed project seeks to investigate both short- and long-term responses of Sonora mud turtles to the extreme, carbonate-rich environment of Montezuma Well. 


\section{Acknowledgments}

The National Park Service has whole-heartedly supported this project from its inception and initial planning through to completion of fieldwork in 2008. We especially thank Biologist Dennis Casper and Superintendent Kathy Davis, Montezuma Castle National Monument, and Ecologist Michele Girard, Southern Arizona Group Office. National Park Service staff at Montezuma Well were enthusiastic and welcoming in their support and generously assisted with logistics of fieldwork and in sharing their knowledge of the Well. Special thanks go to Ranger Rex Vanderford for his enthusiasm and help. Sonja Ollig provided much assistance with setting and checking traps in 2008. Other NPS staff, USGS staff, and volunteers who helped with fieldwork included Lisa Gelczis, Ted Kennedy, Kristen Mahler, Adam Martell, and Paul Ollig. The data, observations, and reports of past researchers at Montezuma Well were invaluable for the work reported here. For their past work and continued help and advice on the turtles of Montezuma Well, we are very grateful to Phil Rosen of the University of Arizona, Steve Garber, and Matthew Malone. Dean Blinn is a font of knowledge on all aspects of the ecology of Montezuma Well, and he has generously shared his knowledge and insights. Cristina Jones and Tom Jones of the Arizona Game and Fish Department assisted with permits and with their knowledge of the Arizona herpetofauna. Lew Coggins provided valuable advice and discussion on turtle population estimates. Major funding for this study was provided by the Western National Parks Association through Contract \# 08-07 (2) and by the National Park Service, Montezuma Castle National Monument. The USGS Southwest Biological Science Center provided support for Lovich and Drost and also supported transportation and vehicle costs. J. Whitfield Gibbons and Erika Nowak reviewed earlier reports for this study. 


\section{References Cited}

American Society of Ichthyologists and Herpetologists, 2004, Guidelines for use of live amphibians and reptiles in field and laboratory research: American Society of Ichthyologists and Herpetologists, accessed at http://www.asih.org/files/hacc-final.pdf.

Auth, D.L., 1975, Behavioral ecology of basking in the yellow-bellied turtle, Chrysemys scripta scripta (Schoepff): Bulletin of the Florida State Museum. Biological Sciences, v. 20, p. 1-45.

Blinn, D.W., 2008, The extreme environment, trophic structure, and ecosystem dynamics of a large, fishless desert spring-Montezuma Well, Arizona, in Stevens, L.E., and Meretsky, V.J. eds., Aridland springs in North America: Tucson, University of Arizona Press, p. 98-126.

Blinn, D.W., and Sanderson, M., 1989, Aquatic insects in Montezuma Well, Arizona, USA-A travertine spring mound with high alkalinity and dissolved carbon dioxide: Great Basin Naturalist, v. 49, p. 85-88.

Boucher, P., Blinn, D.W., and Johnson, D.B., 1984, Phytoplankton ecology in an unusually stable environment (Montezuma Well, Arizona, U.S.A.): Hydrobiologia, v.119, p. 149-160.

Brattstrom, B.H., 1965, Body temperatures of reptiles: American Midland Naturalist, v. 73, p. 376-422.

Burke, V.J., Lovich, J.E., and Gibbons, J.W., 2000, Aquatic and semi-aquatic turtles in Klemmens, M., ed., Conservation of turtles: Washington, D.C., Smithsonian Institution Press, p. $156-179$.

Cadi, A., and Joly, P, 2003, Competition for basking places between the endangered European pond turtle (Emys orbicularis galloitalica) and the introduced red-eared slider (Trachemys scripta elegans): Canadian Journal of Zoology, v. 81, p. 1392-1398.

Cadi, A., and Joly, P., 2004, Impact of the introduction of the red-eared slider (Trachemys scripta elegans) on survival rates of the European pond turtle (Emys orbicularis): Biodiversity and Conservation, v. 13, p. 2511-2518.

Cole, G.A., and Barry, W.T., 1973, Montezuma Well, Arizona, as a habitat: Journal of the Arizona Academy of Science, v. 8, p. 7-13.

Congdon, J.D., Dunham, A.E., and van Loben Sels, R.C., 1993, Delayed sexual maturity and demographics of Blanding's turtles: implications for conservation and management of longlived organisms: Conservation Biology, v. 7, p. 826-833.

Crooks, K.R., and Soulé, M.E., 1999, Mesopredator release and avifaunal extinctions in a fragmented system: Nature, v. 400, p. 563-566.

da Silva, E., and Blasco, M., 1995, Trachemys scripta elegans in Southwestern Spain: Herpetological Review, v. 26, p. 133-134.

Ernst, C.H., and Barbour R.W., 1989, Turtles of the world: Washington, D.C., Smithsonian Institution Press, $313 \mathrm{p}$.

Ernst, C.H., and Lovich, J.E., 2009, Turtles of the United States and Canada: Baltimore, MD, Johns Hopkins University Press.

Gibbons, J.W., 1988, Turtle population studies: Carolina Tips, v. 51, p. 45-47.

Gibbons, J.W., 1990, Life history and ecology of the slider turtle: Washington, D.C., Smithsonian Institution Press, 368 p.

Gibbons, J.W., and Lovich, J.E., 1990, Sexual dimorphism in turtles with emphasis on the slider turtle (Trachemys scripta): Herpetological Monographs, v. 4, p. 129.

Gibbons, J.W., and Semlitsch, R.D., 1981, Terrestrial drift fences with pitfall traps: An effective technique for quantitative sampling of animal populations: Brimleyana, v. 7, p. 1-6 
Hall, D.H., and Steidl, R.J., 2007, Movements, activity, and spacing of Sonoran mud turtles (Kinosternon sonoriense) in interrupted mountain streams: Copeia, v. 2007, p. 403-412.

Hinton, T.G., Fledderman, P., Lovich, J., Congdon, J., and Gibbons, J.W., 1997, Radiographic determination of fecundity: Is the technique safe for developing turtle embryos?: Chelonian Conservation and Biology, v. 2, p. 409-414.

Holland, D.C., 1994, The western pond turtle: habitat and history: Portland, Oreg., U.S.

Department of Energy, Bonneville Power Administration, 11 chapters + appendices.

Hulse, A.C., 1974, An autecological study of Kinosternon sonoriense LeConte (Chelonia:

Kinosternidae): Arizona State University, Ph.D. Dissertation, 105 p.

Hulse, A.C., 1976, Growth and morphometrics of Kinosternon sonoriense (Reptilia, Testudines, Kinosternidae): Journal of Herpetology, v. 10, p. 341-348.

Hulse, A.C., 1982, Reproduction and population structure in the turtle, Kinosternon sonoriense: Southwestern Naturalist, v. 27, p. 447-456.

Lovich, J.E., 1988, Aggressive basking behavior in eastern painted turtles (Chrysemys picta picta): Herpetologica, v. 44, p. 197202.

Lovich, J.E., and Gibbons, J.W., 1990, Age at maturity influences adult sex ratio in the turtle Malaclemys terrapin: Oikos, v. 59, p. 126-134.

Lovich, J.E., McCoy, C.J., and Garstka, W.R., 1990, The development and significance of melanism in the slider turtle, in Gibbons, J.W., ed., Life History and Ecology of the Slider Turtle: Washington, D.C., Smithsonian Institution Press, p. 233254

Lovich, J.E., Medica, P., Avery, H., Meyer, K., Bowser, G., and Brown, A., 1999, Studies of reproductive output of the desert tortoise at Joshua Tree National Park, the Mojave National Preserve, and comparative sites: Park Science, v. 19, p. 22-24.

Malone, M., 1999, Baseline analysis of a Sonoran mud turtle (Kinosternon sonoriense) population at Montezuma Well National Monument, Camp Verde, Arizona: Prescott, Ariz., Embry-Riddle Aeronautical University, Bachelors of Science Thesis.

National Park Service, 1996, A strategic plan for managing invasive nonnative plants on National Park System lands: National Park Service, accessed at http://www.nature.nps.gov/biology/invasivespecies/strat_pl.htm.

National Park Service, 2004, Controlling invasive species: National Park Service, Natural

Resource Year in Review, accessed at http://www.nature.nps.gov/yearinreview/yir2004/02_A.html.

O'Brien, C., and Blinn, D.W., 1999, The endemic spring snail Pyrgulopsis montezumensis in a high $\mathrm{CO} 2$ environment: importance of extreme chemical habitats as refugia: Freshwater Biology, v. 42, p. 225-234.

Rosen, P.C., 1987, Variation in the female reproduction among populations of Sonoran mud turtles, Kinosternon sonoriense: Tempe, Ariz., Arizona State University, M.S. Thesis, 80 p.

Rowlands, P.G., 1999, Vegetation survey of Montezuma Castle National Monument: Camp Verde, Ariz., National Park Service Report to Montezuma Castle National Monument.

Schmidt, C., Drost, C.A., and Halvorson, W.L., 2006, Vascular plant and vertebrate inventory of Montezuma Castle National Monument: U.S. Geological Survey Open-File Report 2006-1163, $56 \mathrm{p}$.

Spinks, P., Pauly, G., Crayon, J., and Shaffer, H.B., 2003, Survival of the western pond turtle (Emys marmorata) in an urban California environment: Biological Conservation, v. 113, p. 257-267.

Temple, S.A., 1987, Predation on turtle nests increases near ecological edges: Copeia, v. 1987, p. $250-252$. 
White, G.C., Anderson, D.R., Burnham, K.P., and Otis, D.L., 1982, Capture-recapture and removal methods for sampling closed populations: Los Alamos, N. Mex., Los Alamos National Laboratory, xvi+235 p. 


\section{Appendix 1. Description of morphological measurements and associated codes used in a study of Sonora mud turtles at Montezuma Well, Arizona}

CAR_LN, Carapace length: greatest length of carapace, not including anterior or posterior notches in shell (in mm)

CAR_WD_MAX, Carapace width: maximum width of carapace (mm)

CAR_WD_45, Carapace width 4-5: width of carapace measured at the junction of the 4th and 5th marginal scutes on either side $(\mathrm{mm})$

CAR_HT, Carapace height: maximum height of carapace (mm)

PLA_MX_ANT, Maximum plastron length/anterior: length of the anterior part of the plastron (from the hinge forward), not including anterior notch in plastron $(\mathrm{mm})$

PLA_MX_POS, Maximum plastron length/posterior: length of the posterior part of the plastron (from the hinge back), not including any posterior notch in plastron $(\mathrm{mm})$

PLA_MX, Maximum plastron length/total: maximum length of plastron, not counting notches (either the sum of pla_mx_ant and pla_mx_pos for mud turtles, or the straight-line maximum length for sliders) (mm)

PLA_NO_ANT, Plastron notch length/anterior: length of the anterior part of the plastron (from the hinge forward), measured to the anterior notch in the plastron, if any $(\mathrm{mm})$

PLA_NO_POS, Plastron notch length/posterior: length of the posterior part of the plastron (from the hinge back), measured to the posterior notch, if any $(\mathrm{mm})$

PLA_NO, Plastron notch length/total: length of plastron, from anterior notch to posterior notch (either the sum of pla_no_ant and pla_no_pos for mud turtles, or the straight-line notch length for sliders) (mm)

PLA_WD, Plastron width: width of plastron at the hinge ( $\mathrm{mm})$

Straightline length

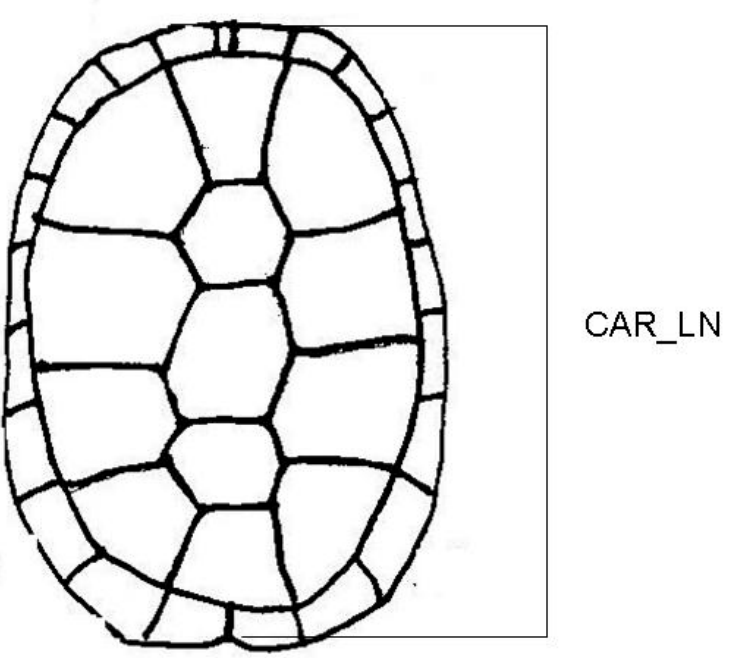


Appendix 1 (continued)
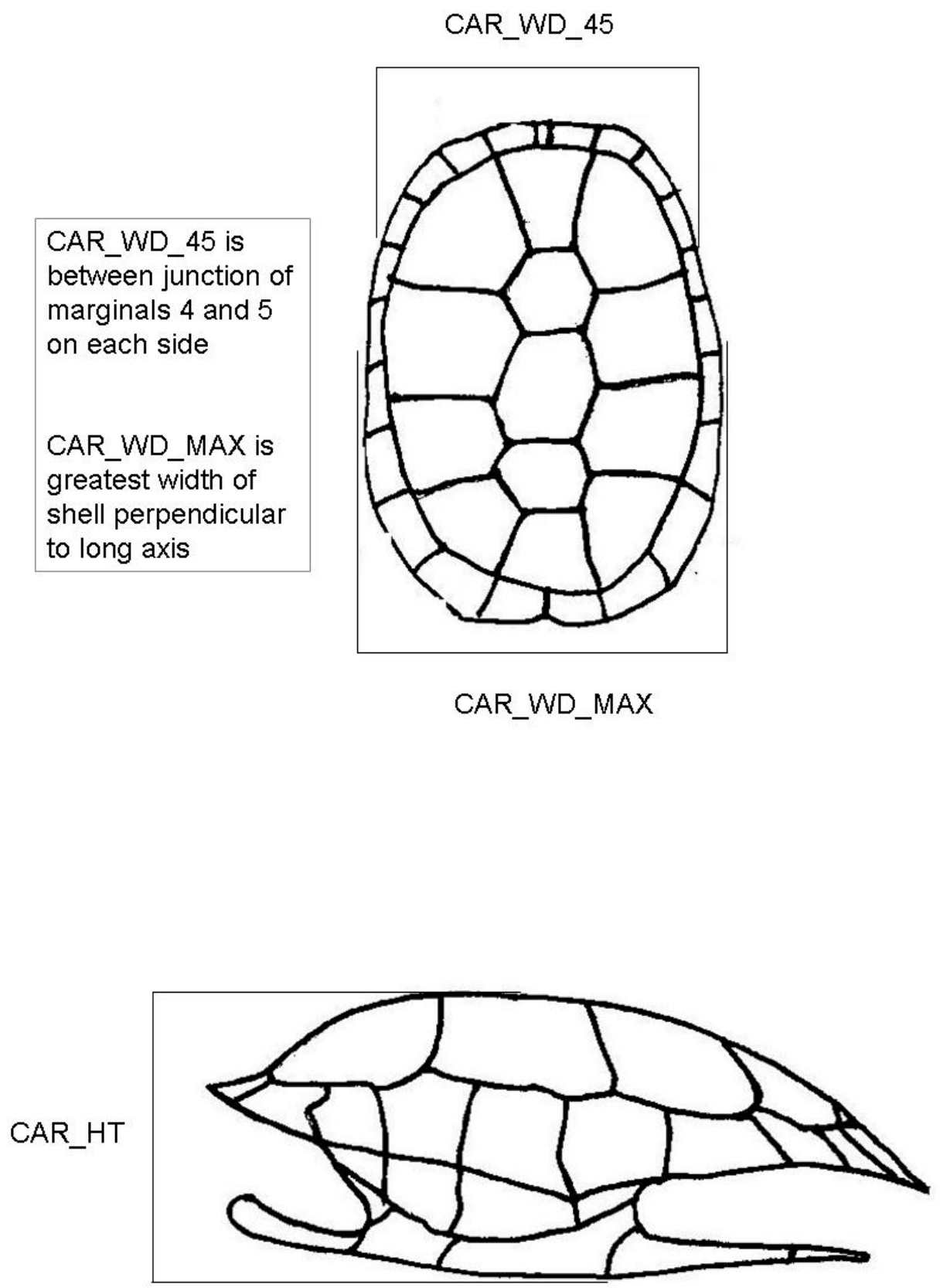

Greatest shell height 
Appendix 1 (continued)

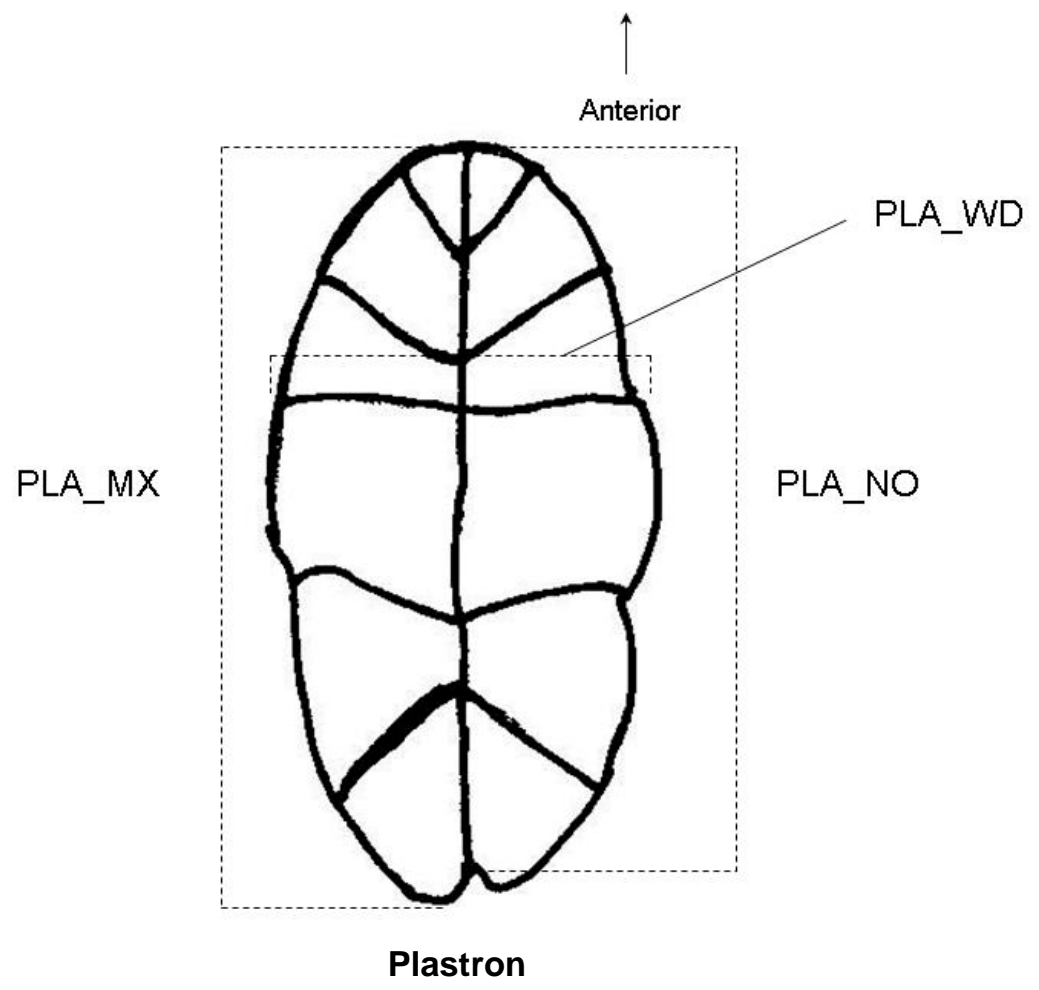




\section{Appendix 2. Population monitoring scheme for turtles at Montezuma Well}

This population monitoring program is based on the basking and behavioral observations conducted in 2007 and 2008 as part of a removal effort for nonnative turtles and an accompanying research study on the Sonora mud turtle. The person who carries out the monitoring should be a careful and attentive observer, with good skills with binoculars and spotting scopes, as well as good note-taking skills. The individual should be trained by going through a survey session with one of the authors of this report (Drost, Lovich, Madrak, or Monatesti) to become familiar with both the observation and data recording process and the characteristics of the turtles and their behavior. Ideally, the same person should conduct all observations throughout the year to ensure consistency and comparability of observations.

Observations should be conducted beginning in April and continuing through August, with four observation periods per month. Observation sessions consist of 3 consecutive hours, alternating morning (8:00-11:00 a.m.) and early afternoon (11:00 a.m.-2:00 p.m.) - so there will be two morning surveys per month, and two afternoon surveys per month. The total number of observation periods will be 20 per yr, with $60 \mathrm{~h}$ total observation time.

Observations are conducted from selected points along the rim of Montezuma Well (the Well) - primarily the visitor overlook at the top of the trail on the southwest rim of the Well and a point approximately midway along the north rim of the Well (the latter point accessed from the trail approximately $10 \mathrm{~m}$ southwest of the overlook; try to walk from rock to rock when getting off the trail to avoid creating a conspicuous path that visitors will be tempted to follow). When scanning from points along the rim away from the visitor overlook (where there is a guardrail) be very careful, particularly when looking through binoculars - it is easy to lose your balance. If you are looking from right along the edge, you should find a safe place to sit while you are scanning - sitting is much safer, and you will also be better able to hold the binoculars steady.

Using the attached data sheet, record locations and numbers of turtles seen at 15-minute intervals. Visually scan for turtles swimming or floating at the surface and use binoculars to scan the shoreline, including rocks, floating or emergent logs and sticks, and other potential basking sites. Also scan all areas of aquatic plants for turtles sitting on top of the plants or for their heads poking up out of the plants. The spotting scope may be used to confirm identifications of turtles and to more closely scan distant areas of shoreline and rocks. Given the time it typically takes to look over the surface of the Well, to scan the shoreline and rocks and other potential basking sites, and to identify and make notes on the turtles seen, you will be observing virtually throughout the entire session, but turtles seen should be assigned to one of the 15-minute intervals (for example, if a turtle is seen after the 9:15 time block, it should be noted on the datasheet for the 9:30 time block).

Note the time, species, number (if more than one individual in a single area), location, activity, and any interactions observed between turtles. For location, use the attached map to determine the grid cell that the turtle is observed in. If a turtle is swimming, its location can be recorded as the cell it was originally seen in, and the cell it ended up in (for example, 98->118). It may help in some instances to record a descriptive location, in addition to the grid cell location. Categorize the behavior of the turtles as S, swimming, either moving along the surface, or coming to the surface, then diving down; B, basking, sitting up out of the water on rocks, sticks, or logs; or A, aquatic basking, turtles floating more or less motionless at the surface for extended periods (longer than $1 \mathrm{~min}$ ). Turtles that are mostly submerged and not moving in dense areas of aquatic plants should also be recorded as aquatic basking. Note unusual observations, questions on identification, or other additional detail in the Comments column on the data sheet.

Record weather conditions (air temperature, cloud cover, wind speed, and relative humidity) at the beginning and end of observations, and at hourly intervals during the observations. Note other species and numbers seen (for example, muskrats, ducks, grebes, etc.) on a separate summary sheet for the day. Some visitors will ask what you are doing when you are at the visitor overlook, and this is an excellent opportunity to discuss the turtle project and other aspects of the biology of the Well. However, be sure to maintain your observation schedule as you talk to them. 
Date:

Observer:

Air Temperature:

Water Temperature:
\%Cloud Cover:

Sun Condition:

Wind Max:

Wind Avg:

\begin{tabular}{|c|c|c|c|c|c|c|c|}
\hline Time & KISO & $\begin{array}{l}\text { TRSC } \\
\text { (Unknown) }\end{array}$ & $\begin{array}{l}\text { TRSC } \\
\text { (Male) }\end{array}$ & $\begin{array}{l}\text { TRSC } \\
\text { (Female) }\end{array}$ & $\begin{array}{l}\text { Grid } \\
\text { location }\end{array}$ & $\begin{array}{l}\text { Behavior (B, } \\
\mathrm{AB}, \mathrm{S})\end{array}$ & Comments \\
\hline & & & & & & & \\
\hline & & & & & & & \\
\hline & & & & & & & \\
\hline & & & & & & & \\
\hline & & & & & & & \\
\hline & & & & & & & \\
\hline & & & & & & & \\
\hline & & & & & & & \\
\hline & & & & & & & \\
\hline & & & & & & & \\
\hline & & & & & & & \\
\hline & & & & & & & \\
\hline & & & & & & & \\
\hline & & & & & & & \\
\hline & & & & & & & \\
\hline & & & & & & & \\
\hline & & & & & & & \\
\hline
\end{tabular}




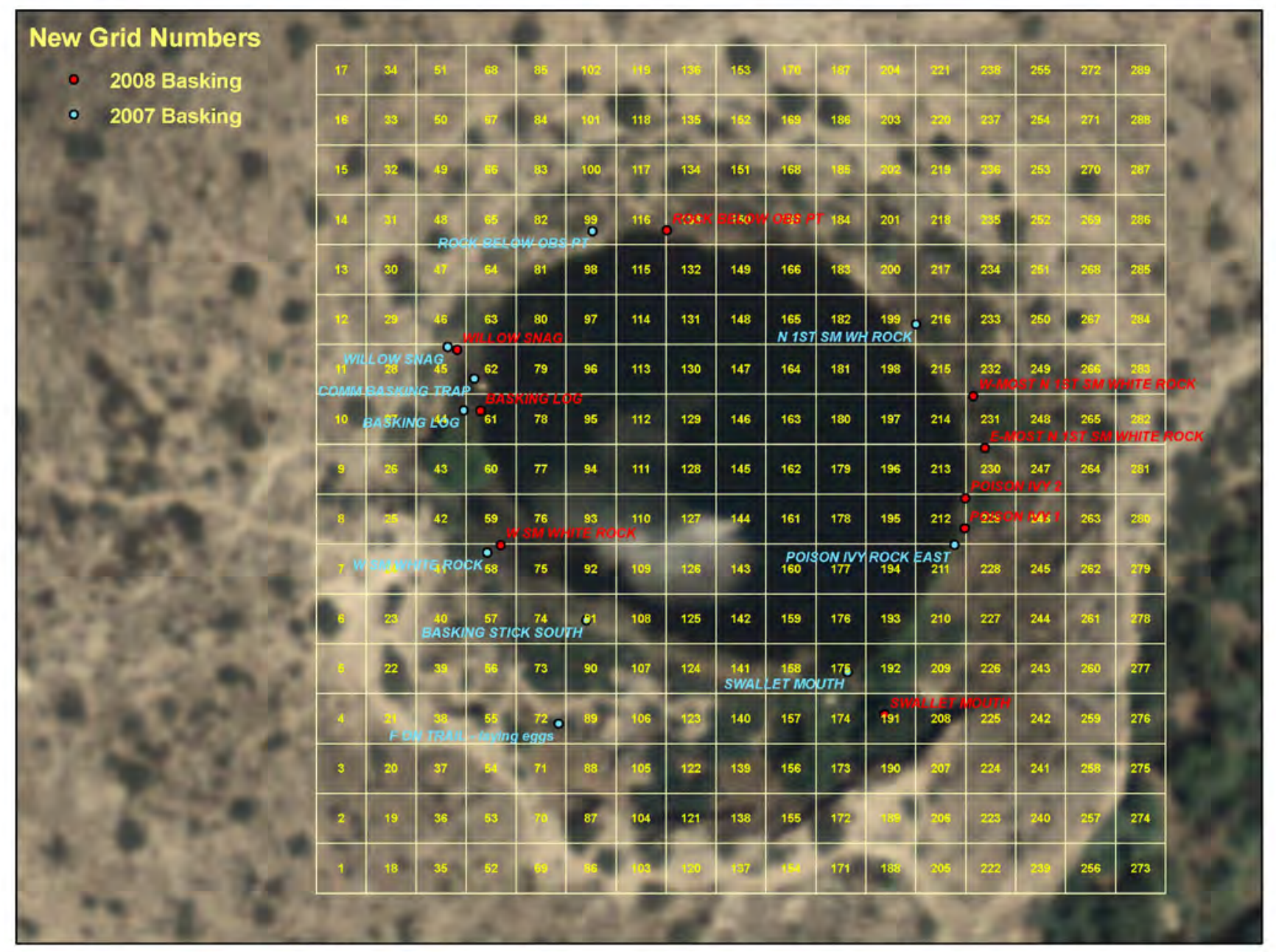

Appendix 2 (continued). Aerial image of Montezuma Well with grid overlay and points for noting locations of turtles. Numbered points are landmarks - sites frequently used by turtles or features useful for orienting to locations within the Well. Names for the points are as follows:

106 North first small white rock

107 Rock below observation point

108 Willow snag

109 Commercial basking trap (original location)

110 Basking $\log$ (location as of 2008)

111 West small white rock

112 Basking stick, south

113 Poison ivy rock east

114 Well outlet/swallet mouth 
This page intentionally left blank 
음 